\title{
Biomedical engineer's guide to the clinical aspects of intensive care mechanical ventilation
}

\author{
Vincent J. Major ${ }^{1 *}$, Yeong Shiong Chiew², Geoffrey M. Shaw ${ }^{3}$ and J. Geoffrey Chase ${ }^{4}$
}

\section{*Correspondence:}

vincent.major@nyulangone. org

${ }^{1}$ Department of Population Health, NYU Langone Health, New York, NY, USA Full list of author information is available at the end of the article

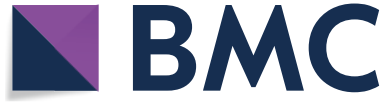

(c) The Author(s) 2018. This article is distributed under the terms of the Creative Commons Attribution 4.0 International License (http://creativecommons.org/licenses/by/4.0/), which permits unrestricted use, distribution, and reproduction in any medium, provided you give appropriate credit to the original author(s) and the source, provide a link to the Creative Commons license, and indicate if changes were made. The Creative Commons Public Domain Dedication waiver (http://creativecommons.org/publi cdomain/zero/1.0/) applies to the data made available in this article, unless otherwise stated.
Discussion: This review presents the significant clinical aspects and variables of ventilation management, the potential risks associated with suboptimal ventilation management, and a review of the major recent attempts to improve ventilation in the context of these variables. The unique aspect of this review is a focus on these key elements relevant to engineering new approaches. In particular, the need for ventilation strategies which consider, and directly account for, the significant differences in patient condition, disease etiology, and progression within patients is demonstrated with the subsequent requirement for optimal ventilation strategies to titrate for patient- and time-specific conditions.

Conclusion: Engineered, protective lung strategies that can directly account for and manage inter- and intra-patient variability thus offer great potential to improve both individual care, as well as cohort clinical outcomes.

Keywords: Mechanical ventilation, Intensive care, Respiratory failure, Model-based treatment, Patient-specific ventilation, Protective lung strategies 


\section{Background}

In intensive care, mechanical ventilation (MV) is the primary support for patients with respiratory failure or acute respiratory distress syndrome (ARDS) despite decades of research [1]. MV is an essential life support, but if non-optimally managed, it can also degrade patient condition [2,3]. MV provides positive airway pressure and airflow to support work of breathing, sustain oxygenation and enable patient recovery. In particular, the goal of MV is to provide these supports while protecting the lung from further damage $[1,4]$. However, while there is some general agreement on which MV settings and clinical parameters are preferred $[1,5,6]$, there are limited guidelines and conflicting trial results [7-13] in optimising MV support, resulting in variable MV settings. (Please refer to these recent reviews of clinical advances in treatment [1] and challenges [14] of MV for ARDS.) Moreover, MV care and guidelines are almost entirely clinically determined in contrast to the area of diabetes/metabolism, for example, which has a long history of mathematical and engineering research that has driven recent advances in care.

An example of highly variable MV settings is the positive end-expiratory pressure (PEEP). Some may consider lower PEEP superior and safer $[15,16]$. However, lower PEEP can lead to increased cases of oxygen desaturation and hypoxemia $[8,17]$ and atelectrauma, indicated by a greater number of rescue therapies and death after rescue therapy [13]. In contrast, higher PEEP can increase recruitment of collapsed lung units [18-20], stabilising injured or collapsed alveoli [21, 22], reducing inflammatory mediators in plasma and bronchoalveolar lavage fluid [23]. However, higher PEEP can also cause ventilator induced lung injury (VILI) $[8,13]$. Hence, there is no consensus on the best PEEP, which can vary between and within patients.

Optimal settings are patient-specific and likely evolve over time, and are thus not easily titrated using standard clinical protocols. Because current tools and methods cannot provide enough insight into patient-specific response to MV in real-time [24], particularly breath-to-breath or hour-to-hour, and non-invasively, the best approach in setting MV remains uncertain [3, 13, 21, 22, 24-27]. As a result, the current standard of MV therapy in the intensive care unit (ICU) relies heavily on clinician experience and intuition, or a generalised one size fits all approach, such as setting MV for acute respiratory distress syndrome (ARDS) patients using the ARDSNet or lung protective strategies recommendations $[5,8,10,11]$. Therefore, patient-specific MV methods are needed to improve individual patient outcomes beyond where they are today [24].

More specifically, the use of biomedical devices and model-based methods enable broader and wider perspective on patient-specific condition in setting MV [24]. However, research in this area is still lacking. Of particular concern, is that MV is a highly integrated field, mixing medical knowledge with engineering technologies, including control systems, signal processing and mechatronics. As such, technologists and engineers rely heavily on clinical expertise for guidance, potentially without proper understanding of the problem, creating a need to bridge this lack of medical knowledge.

This paper addresses this issue via a comprehensive review of the clinical aspects and application of MV for readers of both clinical and non-clinical expertise. A fundamental introduction to MV is included first to define the clinical terminology used throughout and to organize the review, which, despite being medically focused, aims to maximize comprehension by non-clinical readers and offer entry points from the engineering 
perspective to understand the fundamental mechanics at play. In particular, the variables and mechanics of MV are placed in a structure that is also suitable for engineering mechanics analysis, with relevant clinical references on their use.

The article covers the adverse effects of suboptimal MV settings, before discussing several large clinical randomised controlled trials concerning different MV strategies and recent trends, all of which set the clinical context and better define the clinical shortfalls that exist today. The MV strategies presented are classified into families based on how they intend to mitigate the challenges of MV. This is a new method of assessing the field and translating engineering solutions to medical problems, and vice versa. The overall goal is to delineate the clinical state of the art to highlight the need for patientspecific methods in standardising MV settings, ending with a particular focus on how novel engineering, modelling and simulation approaches to measurement, control and/ or management could have significant clinical impact. It thus provides a clinical state of the art tutorial review to motivate potential avenues for future engineering science research to transform this ubiquitous critical care therapy.

Hence, the overall goal of this review is to provide a broad overview, particularly for non-specialists or those new to this area so they can rapidly assimilate the state of the art, rather than a detailed, systematic review of a particular facet, clinical or engineering. Thus, in this case, the review covers both clinical definitions, to introduce terminology and its clinical and engineering meaning, as well as to discuss the clinical state of the art, and further provide context for the mechanics and biomedical engineering aspects. As a result, some areas may appear overly simplified, to those familiar with that portion of the problem, but are necessary for those who are seeking a foothold. Throughout, we will attempt to point the reader to recent, more specific, reviews that encompass the greater research area.

\section{Fundamentals of mechanical ventilation Mechanical ventilation parameters}

Key parameters of MV supported breathing cycles include: tidal volume, airway pressure, peak inspiratory pressure, plateau pressure, positive end-expiratory pressure, fraction of inspired oxygen, respiratory rate and inspiration to expiration ratio.

\section{Tidal volume $\left(V_{t}\right)$}

Physically, $V_{t}$ is the air volume entering and exiting the lungs each breath. $V_{t}$ is chosen by the clinician, usually using predicted body weight, and for ARDS patients $\mathrm{V}_{\mathrm{t}}$ between 4 and $8 \mathrm{~mL} / \mathrm{kg}$ is recommended [28]. Higher tidal volume can assist with removal of carbon dioxide from the lung in patients with hypercapnia or delivery of oxygen to patients that have hypoxemia. However, excessive volumes can also overinflate and stretch lung tissue causing injury $[29,30]$.

\section{Fraction of inspired oxygen (FiO2)}

$\mathrm{FiO}_{2}$ is the oxygen concentration delivered to the patient. Higher $\mathrm{FiO}_{2}$ enables better exchange oxygen from the lungs into the blood, increasing the partial pressure of oxygen in the alveoli and thus the rate of diffusion. $\mathrm{FiO}_{2}$ above $21 \%$ (atmospheric air) is often used to increase oxygenation, while avoiding the risks associated with delivering 
higher pressures and tidal volumes, or when collapsed alveoli are not recruitable [31]. However, excessive $\mathrm{O}_{2}$ partial pressures can cause oxygen toxicity [32, 33].

\section{Airway pressure $\left(P_{\text {aw }}\right)$}

The $P_{a w}$ is the pressure supplied from the ventilator to the patient during MV. There are four distinct measures of $P_{a w}$ during a typical MV breathing cycle:

- Positive end expiratory pressure (PEEP): PEEP is the elevated airway pressure at the end of expiration. PEEP is an important setting used to maintain lung recruitment to allow gas-exchange [34, 35]. It also prevents the cyclic opening and closing of collapsed lung units (atelectasis), which can cause further damage [2, 30]. Titrating PEEP is often a topic of debate, with some advocating higher levels, and some lower levels [8]. It is currently most often set using the PEEP-FiO2 table [5].

- Peak inspiratory pressure (PIP): PIP is the maximum airway pressure during inspiration. PIP is limited to avoid excessive pressures causing further injury [2, 36, 37]. PIP may be limited in pressure control modes where the pressure range can be set.

- Plateau pressure $\left(P_{\text {plat }}\right)$ : Plateau pressure is the airway pressure measured during an end of inspiratory pause [38]. Compared to PIP, this pressure level is lower, as it is not influenced by the dynamic pressure differences due airway resistance. This pressure level is used as a representation of the pressure in the alveoli, and is often used as a threshold for high-pressure levels. Typically, airway pressure is set at pressure level where $P_{\text {plat }}$ is less than $30-35 \mathrm{cmH}_{2} \mathrm{O}$ to avoid barotrauma [39].

- Driving pressure $(\Delta P): \Delta \mathrm{P}$ is the pressure difference added above PEEP to $P_{\text {plat }}$. Recent post hoc and meta-analyses have suggested that driving pressure may be more important than other MV parameters determining outcomes [40, 41] that higher driving pressures are associated with increased mortality [42]. Crucially, these results and, any new guidelines, must consider $\Delta \mathrm{P}$ with respect to at least one of PEEP and $P_{\text {plat }}$.

The four primary $P_{a w}$ measures do not completely define a breath cycle but, as described in Fig. 1, do measure the extremes of both inspiration and expiration. Together with the time components, this set of metrics can roughly describe the entire breathing cycle with only minimal redundancy.

\section{Respiratory rate (RR) and inspiration to expiration (l:E) ratio}

The RR during MV is the number of breaths per minute. It is commonly around 16-20 so that each breath is approximately $3-4 \mathrm{~s}$ in length. During fully controlled ventilation, within the length of each breath (corresponding to the RR), clinicians can adjust the I:E ratio-the ratio of inspiration time to expiration time-to ensure adequate ventilation of carbon dioxide out of the lung. Setting RR together with $V t$ also ensure adequate minute ventilation (litres of air per minute). Spontaneously breathing patients on support modes set RR themselves, and hybrid modes, such as mandatory ventilation, ensure a minimum allowable $R R$ is met. 


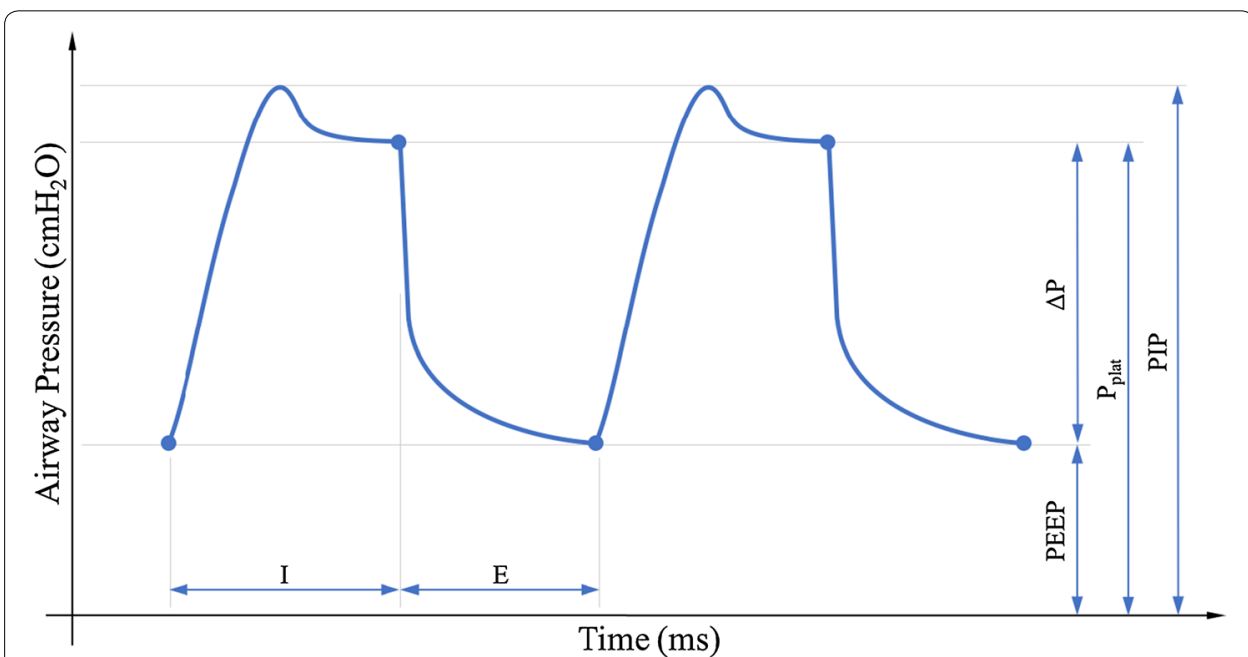

Fig. 1 An idealized MV breath cycle highlighting common pressure measurements including positive end expiratory pressure $(P E E P)$, driving pressure $(\triangle P)$, peak inspiratory pressure $(P I P)$, and plateau pressure $\left(P_{\text {plat }}\right)$ and the two time components, inspiration (I) and expiration (E), that determine the I:E ratio. These measures are the most commonly monitored in practice and employed in modelling and moreover as a set can roughly describe both inspiration and expiration

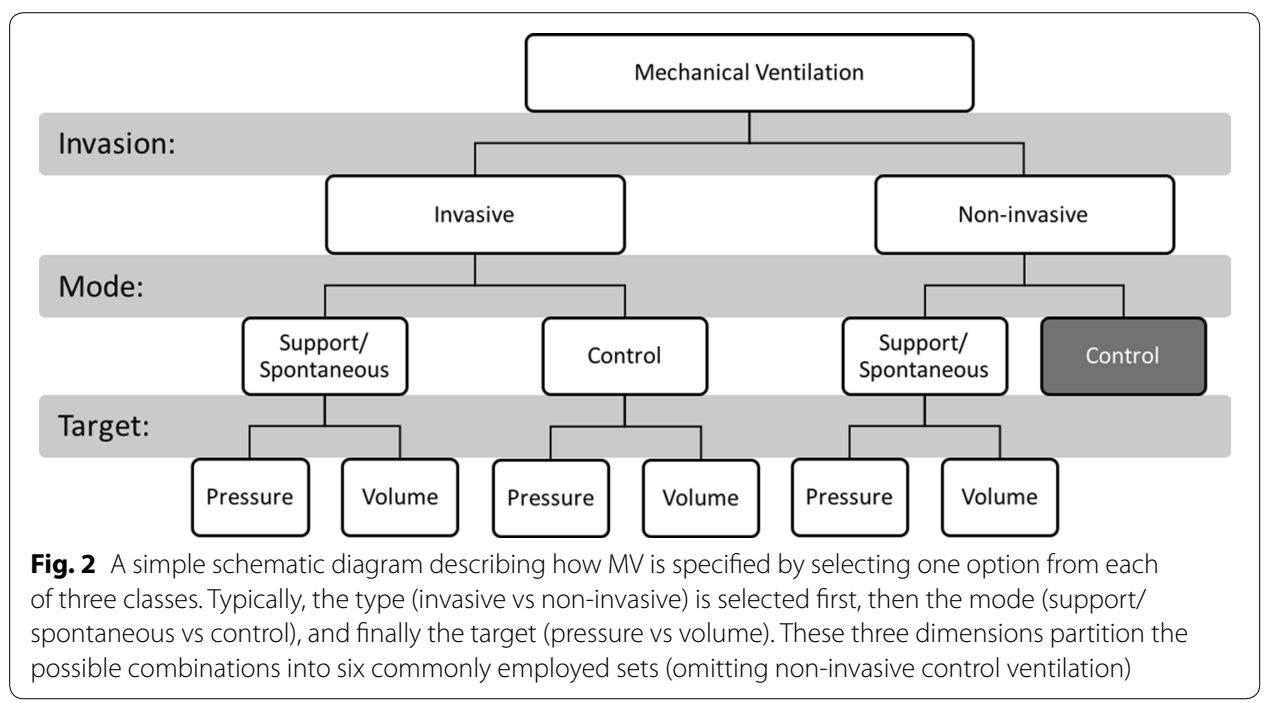

\section{Ventilation modes}

Fundamentally, ventilation can be divided into several groups by the level of invasion, the mode used and the target. Typically, MV is first split into invasive or non-invasive, determined if the patient is intubated or not, and then subdivided into control or support modes, depending on the patient's breathing efforts and sedation, and finally, pressure or volume controlled modes [43-45]. Figure 2 describes three tiers that roughly align with the decision-making process to completely define each of the three dimensions. The box representing control mode non-invasive ventilation is shaded to designate that this combination of settings is rarely employed [45]. Please refer to a recent review of ventilation modes and settings in the context of non-invasive ventilation [45]. 
1. Invasive versus non-invasive:

- MV can be delivered invasive or non-invasively. Invasive ventilation involves insertion of an endotracheal tube or tracheotomy, whereas non-invasive ventilation (NIV) is delivered via face mask [46]. Invasive ventilation is most common when the ventilator is required to manage the entire patient work of breathing.

- The application of NIV for ARDS remains controversial. Implementation of NIV requires more training of clinical staff [47], remains complicated to correctly identify ARDS patients that are likely to benefit [48], and NIV failure, leading to intubation, is common [49]. In a recent study of 2800 ARDS patients, 15\% received NIV and failure rates ranged from 22 to $47 \%$ for patients with mild and severe ARDS with hospital mortality rates tripling for patients with NIV failure (45\% vs $15 \%$ for success) [50]. However, NIV is actively being improved as evidenced by a recent study that terminated early for efficacy. The authors compared outcomes of ARDS patients treated with NIV delivered by helmet, compared to a typical face mask and observed that intubation rates dropped, ventilator free days increased, and 90 day mortality rates decreased [51].

2. Control versus support modes:

- Control ventilation modes strictly adhere to the chosen ventilation strategy, and are commonly used for patients who are heavily sedated, paralyzed, or cannot breathe regularly enough to support themselves. They provide all the work of breathing.

- Support ventilation modes act as an assistant to patients who are breathing spontaneously. Unlike controlled modes, support MV delivers breathing cycles when triggered by patients.

- Currently, hybrid modes, such as synchronized intermittent mandatory ventilation (SIMV), allow patients to control the timing of their breathing, while offering up to full support, but also ensure that mandatory breaths are given to the patient when no spontaneous effort is made. Hybrid modes ameliorate the limitations of set modes.

3. Pressure versus volume control methods:

- Pressure control fundamentally controls the input and output pressure of the ventilation. This mode allows precise limitation of the maximum PIP to prevent barotrauma [52]. During pressure control, the airflow and tidal volume are delivered depending on the controlled pressure.

- Volume control methods enable a set minimal tidal volume during ventilation. In return, the airway pressure is thus determined by the flow and tidal volume profile.

- Similar to control and support modes, hybrids between pressure and volume control ventilation modes have emerged to provide the advantages of both modes [53]. 


\section{MV outcome measurements}

The quality of MV delivery is often assessed using outcome measurements or surrogates. The following are several outcome measurements often assessed.

Blood oxygenation can be measured using arterial blood gas information, partial pressure of oxygen $\left(\mathrm{PaO}_{2}\right)$, or using pulse oximetry, peripheral capillary oxygen saturation $\left(\mathrm{SpO}_{2}\right)$. Blood oxygenation is the most common monitoring metric to ensure ventilation is adequate and delivering sufficient oxygen to the patient. Standard practice aims for minimum $\mathrm{PaO}_{2}>80 \mathrm{mmHg}[54,55]$ and minimum $\mathrm{SpO}_{2}$ on the order of $88-95 \%$ depending on the current $\mathrm{FiO}_{2}[8,10,11]$.

Minute ventilation is the volume of air delivered during $1 \mathrm{~min}$ and is effectively the product of the $R R$ and $V_{t}$ input settings. Target minute ventilation goals are commonly 8-10 L/min for adults $[56,57]$.

Transpulmonary pressure is the pressure difference between the alveoli and the pleural cavity. Airway pressure-the pressure at the airway opening-is easier to measure but may not be as clinically informative as transpulmonary (or esophageal) pressure [58]. One measured airway pressure may not translate into consistent transpulmonary pressures between patients due to the heterogeneity of patient condition [59]. Since the mechanics of lung collapse, recruitment and overdistension depend on the pressure within the lung, transpulmonary pressures are clearly more relevant to the stress and strain applied to the lung and any subsequent injury than measured airway pressure [2, 60]. For this reason, MV should provide adequate transpulmonary pressure to maintain acceptable oxygenation, while minimising both atelectasis and overdistension [2, 27]. However, estimated measures of transpulmonary pressure require the use of a highly invasive balloon catheter to measure the pleural pressure [27] and are thus not often applied clinically. Please refer to a recent review discussing applications of transpulmonary (and esophageal) pressure [58].

Lung imaging techniques create images of the lungs for clinicians to assess lung condition, allowing them to treat the patient based on their observation [24]. Computed tomography $(\mathrm{CT})$ is regarded as a gold standard. CT images allow clinicians to assess patient condition, response to PEEP titrations, alveoli recruitment/distension and gas distributions. However, CT for ICU patients is costly, requires transfer to the radiology department or a portable CT machine and further exposes the patient to radiation [24, 61-65]. Hence, it is not a regular care-monitoring tool.

Portable $X$-rays remain the most common radiographic examination $[64,65]$ as they can be carried out at the bedside and subject the patient to a smaller radiation dose. However, portable radiographs have lower and more variable quality $[63,65]$ and commonly only show one two-dimensional, frontal plane, compared to images in multiple planes with varying slice thickness available in CT, helical CT or other three-dimensional techniques $[64,65]$. Finally, and most importantly, imaging methods that use ionising radiation are not suitable for continuous or semi-continuous monitoring of lung condition. Thus, the application of such imaging techniques to guide therapy remains limited [66].

An emerging form of lung imaging is electrical impedance tomography (EIT). EIT has shown good correlation with $\mathrm{CT}$, such that it has been proposed and recently validated to guide ventilation therapy [67-69]. Commercial EIT systems generate lung images 
using relative impedance changes with respect to end-expiration, allowing ventilation recruitment and inhomogeneity to be monitored in real-time [68, 70]. Several recent studies have demonstrated the utility of EIT at the bedside by titrating PEEP to ensure protective lung strategies balance recruitment without overdistension [71-73]. Moreover, EIT has shown good correlation with CT [74] but is not yet ready to replace CT as a gold standard as the technology is relatively new and costly [75]. A recent review described EIT as clinically validated but noted the literature lacks evidence to its efficacy in clinical outcomes [69]. More studies are thus required for this technology to implement EIT as part of regular patient care. Please refer to these recent reviews for further reading in the clinical $[69,70]$ and bioengineering [76] state of the art.

Other examples of outcome measurements that can quantify the quality of care for mechanically ventilated patients in the ICU include:

- Length of mechanical ventilation (LoMV) and/or ventilation free days (VFD): LoMV is quantified as how long the patient requires mechanical ventilation support and VFD is measured as the number of days free from ventilator support within a 28-day period.

- Mortality: Measured as survived or deceased within a time-period. Common examples are ICU mortality, hospital mortality, 28-day mortality, and 90-day mortality,

- Severity scoring systems: Patient severity scores and metrics are used to account for the severity of the patient's disease state. Several common examples are the Acute Physiology and Chronic Health Evaluation score (APACHE) [77-79], Simplified Acute Physiology Score (SAPS) [80, 81], and Sequential Organ Failure Assessment score (SOFA) [82].

\section{Summary}

ICU MV treatment is managed by setting several basic ventilation parameters, while checking that other measured parameters are within acceptable bounds. This process is further complicated while intermittently making small changes to care based on patient response. It is common to titrate the ventilation parameters manually to ensure all targets are met, while trying to reduce the risk of further injury. The lack of clear consensus combined with the wealth of MV modes and settings ensures significant inter- and intra-patient variability in care.

\section{The problem with MV management} Ventilation induced lung injury (VILI)

MV is a crucial support for patients with respiratory failure. However, this essential treatment can have (unintended) harmful consequences, causing further injury and/or delay to recovery. Ventilator induced lung injury (VILI) is caused by non-optimal MV and manifests as a mechanical injury to alveoli that exacerbates the systemic inflammation [23, 30, 70, 83-91]. It can thus directly increase the risk of death [88], as well as length and cost of ventilation treatment [92].

A normal, healthy person creates a negative-pressure inside the lung by expanding the chest wall and contracting the diaphragm, which creates a negative pressure in the 
pleural cavity, and in the lung itself. When the pressure inside the lung is lower than ambient, air flows into the lung. During expiration, air is exhaled passively, reducing the volume of the lung. Modern MV is comprised of positive-pressure ventilation that drives air and oxygen into the lung during inspiration and lets expiration occur passively. This non-physiological inspiration during MV support, may add stress and strain to lung tissues, resulting in trauma in any of four categories: barotrauma, volutrauma, atelectrauma, and biotrauma or other [2, 93, 94]. For further discussion on the pathophysiology of VILI and several approaches to minimize VILI, please refer to a review by Fan et al. [95].

Barotrauma is injury caused by excessive pressures in the lung. The pressure gradient between the alveoli and the abdomen can cause air to migrate into the interstitial tissue causing many of the manifestations of barotrauma [2, 29]. Early work by Peterson et al. [36] reported that all patients with PEEP $>40$ and/or PIP $>100 \mathrm{cmH}_{2} \mathrm{O}$ developed barotrauma. However, more recently, Weg et al. [96] cast doubt on these results when they compared patients with matching disease states (ARDS induced by sepsis) and reported no significant difference in pneumothorax rates for high pressures or volumes. Thus, the pressure at incidence is likely patient-specific [97]. Overall, barotrauma is a result of driving pressure and/or PEEP that is too high, resulting in excessive PIP and lung pressures.

Volutrauma occurs when ventilation with excessive volume stretches the lung tissue beyond its elastic limit causing injury. It can lead to pulmonary edema, increased fluid filtration, diffuse damage to alveoli, epithelial and microvascular permeability [2, 29]. It is a result of too large tidal volume either by specification or as a result of delivered driving pressure in pressure controlled modes resulting in too much volume expansion.

Atelectrauma is a lung injury that occurs when ventilation with too little volume and/ or pressure causes repeated, cyclic opening and closing of unstable alveoli near the boundary of collapsed and aerated areas $[1,94,98]$. MV uses PEEP and higher airway pressures to recruit alveoli during inspiration. As the pressure drops during expiration, some diseased alveoli collapse and reopen in the next breath. This cyclic opening and closing is a symptom of a PEEP that may be too low to keep such recruited alveoli open. Atelectrauma is common in patients diagnosed with ARDS and may be more significant than originally thought [10]. Hence, patient-specific pressure and PEEP is critical.

Biotrauma is lung injury caused by the body's response to the invasion of MV and is the most difficult lung injury to quantify in a clinical setting. MV can cause increases in alveolar-capillary permeability, surfactant inactivation and the release of inflammatory mediators [99-101]. Slutsky et al. [102] and Murphy et al. [103], noted that it can lead to multiple organ failure. Non-protective ventilation strategies (e.g. $\mathrm{V}_{\mathrm{t}} \sim 12 \mathrm{~mL} / \mathrm{kg}$ and $\mathrm{PEEP}=0 \mathrm{cmH}_{2} \mathrm{O}$ ) are associated with bacterial translocation and the transmission of pulmonary infections and inflammatory mediators into the circulatory system with subsequent systemic inflammation, compared to protective ventilation strategies with moderate PEEP $\left(10-12.5 \mathrm{cmH}_{2} \mathrm{O}\right)$ and lower tidal volume ventilation $(\sim 5 \mathrm{~mL} / \mathrm{kg})$.

Other similar adverse effects of MV include ventilator associated pneumonia [1, 104], pulmonary edema or fluid build-up in the lung $[8,70]$, circulatory depression or a reduction in cardiac output due to increased chest cavity pressures with PEEP [8], oxygen toxicity due to excessive oxygen from $\mathrm{FiO}_{2}[1,2,101]$, and hypercapnia or excessive $\mathrm{CO}_{2}$ 
caused by too little removal of $\mathrm{CO}_{2}$ out of the blood [1]. All of these effects increase the risk of poor patient outcome.

\section{Patient intra- inter variability: disease state and variable treatment response}

The lung of a respiratory failure patient is very heterogeneous [70], with mixed healthy and diseased alveoli, displaying significant inter- and intra-patient variability. Thus, what works for one patient may lead to VILI in another [21, 105]. Equally, what helps some diseased alveoli, such as added pressure, may injure nearby healthy alveoli. The inability to easily assess lung heterogeneity regularly with imaging, or to selectively provide pressure and volume to areas of the lung thus leads to most of the difficulty in optimising care.

Variability between patients (inter-patient) can be driven by heterogeneous disease and response to treatment [1]. Within a cohort of ARDS or respiratory failure patients, the primary diagnosis is often not recorded as ARDS [106, 107], as the etiology of respiratory failure varies with each patient [108, 109], and ARDS may never be diagnosed, limited by clinical interpretation of chest imaging (please refer to a recent review for discussion surrounding the diagnostic limitations of ARDS [1]). ARDS may be caused by both pulmonary and extra-pulmonary insults [1], which has lead to very diverse ARDS, or respiratory failure, study cohorts $[108,109]$. With the diverse causes of respiratory failure comes a wide distribution of lung condition and thus individual patient-specific requirements in optimal ventilation settings.

Disease progression and treatment can affect lung condition and the corresponding optimal ventilation parameters creating variability within one patient (intra-patient) over time. Hence, care must be able to measure appropriate metrics of patient-specific lung condition to evolve over time, as well as trying to ensure care is as optimal as possible at each time point in real-time, rather than intermittently every 6 or $24 \mathrm{~h}$.

Heterogeneity within a patient's lungs can also lead to variability within one patient (intra-patient) during any one breath. Within the ARDS or respiratory failure lung, it is common for some areas to be collapsed (atelectasis) and poorly perfused, while others are normal. MV cannot provide ventilation separately to the heterogeneous lung areas, though one lung ventilation is possible [110]. Considering both lungs, each with significant variability, selection of 'optimal' ventilation settings for overall lung recruitment can provide excessive pressures/volumes to some regions, and too little to others. Lung injury can thus be exacerbated by attempting to provide improved care by further injuring non-aerated, collapsed alveoli. The result is a need to balance, as discussed, the care of injured lung units with the possible harm to unaffected units.

\section{The influence of the definition and diagnosis of respiratory failure patients}

Various pulmonary and extra-pulmonary insults may lead to a patient developing respiratory failure, or the more severe ARDS [1]. The most frequent are pneumonia and extra-pulmonary sepsis [111-113]. The high mortality and morbidity of ARDS patients has made these cohorts a focus of MV research, and optimised MV is critical to outcome $[5,10,114]$.

In 1994, the American-European Consensus Conference (AECC) defined acute lung injury (ALI) and ARDS [115] as a syndrome of acute onset of respiratory failure 
with findings of bilateral infiltrates on chest radiograph. This definition is followed by the absence of elevated left heart filling pressure determined either diagnostically with a pulmonary artery catheter (pulmonary artery occlusion pressure $\left(\mathrm{PaO}_{2}\right)$ of $<18 \mathrm{mmHg}$ ) or clinically (absence of evidence of left arterial hypertension) [115, 116]. A $\mathrm{PaO}_{2} / \mathrm{FiO}_{2}$ (P/F) ratio less than $300 \mathrm{mmHg}$ is considered ALI, and P/F ratio $<200 \mathrm{mmHg}$ is categorised acute respiratory distress syndrome (ARDS).

This definition was updated in 2012, and is referred to as the ARDS Berlin definition [109]. The changes in definition includes: (1) the replacement of ALI with mild, moderate and severe ARDS; (2) PEEP settings; (3) defining the period of acute onset; (4) recognition of CT imaging as diagnostic; and (5) exclusion of hydrostatic pulmonary edema [117]. The new definition is able to better capture the syndrome, but studies have suggested further improvements can be made [118-120].

Following the AECC and Berlin definitions, chest imaging is often performed before a final diagnosis is made. Imaging can delay diagnosis and intervention as well as add subjectivity by interpreting imaging results [1]. In particular, to provide prompt recruitment and maintenance, a recruitment manoeuvre should be performed as soon as possible for any MV patient to open up the lung and assist with gas exchange $[19,20]$. Final diagnosis should then follow patient stabilization.

Equally importantly, ARDS is typically diagnosed at one moment in time near the start of ventilation [121]. However, current MV settings, such as PEEP, at that time can greatly affect both the measured $\mathrm{PaO}_{2}$ and the required $\mathrm{FiO}_{2}$ for adequate oxygenation. Estenssoro et al. [121] reported that PEEP $>0$ during initial ventilation can improve $\mathrm{PaO}_{2}$ so drastically that ARDS may be misdiagnosed if assessment is delayed too long, due to delay in blood gas extraction or waiting for chest imaging results. If each patient had been evaluated $6 \mathrm{~h}$ later, $52 \%$ would no longer fulfil the AECC definition for ARDS $(\mathrm{P} / \mathrm{F}<200)$ and instead be diagnosed with less severe ARDS or ALI [121], possibly changing their overall treatment and care. In this specific study, no RMs were performed, and Estenssoro et al. attributed the improvement in P/F ratio from $<200$ to $>200$ over $24 \mathrm{~h}$ for 18 of the 48 similarly ventilated patients to a relatively higher mean PEEP of $12.8 \mathrm{cmH}_{2} \mathrm{O}$ after $24 \mathrm{~h}$. Thus, initial care choices can interact significantly with the diagnosis made and thus, the subsequent care provided.

Villar et al. [122] conducted a similar trial to Estenssoro et al., where patients were tracked. Approximately $40 \%$ of ARDS patients exhibited an increase in $\mathrm{P} / \mathrm{F}$ ratio to above the AECC threshold when evaluated after $24 \mathrm{~h}$ at $\mathrm{PEEP} \geq 10 \mathrm{cmH}_{2} \mathrm{O}$ and $\mathrm{FiO}_{2} \geq 50 \%$. Villar et al. [123] warns that all respiratory failure patients start off with poor oxygenation and neither the AECC or Berlin definitions allows for re-evaluation of hypoxemia at consistent ventilator settings, especially PEEP and $\mathrm{FiO}_{2}$. The authors recommend use of a PEEP-FiO 2 trial conducted $24 \mathrm{~h}$ after ARDS diagnosis, stating this test would provide an easy and simple strategy to identify subpopulations and provide care based on actual patient risk [123].

Hence, defining and diagnosing ARDS/ALI within respiratory failure is an important step towards distinguishing between severe and moderate respiratory failure [118], and thus to providing appropriate care. However, the diagnosis of ARDS is slow and followed by rapid patient evolution. Care must thus be taken not to misdiagnose 
patients at the wrong time, or equally, to ensure that the diagnostic process does not lead to an inadequate level of care.

What is needed, is a consistent standard of care to provide early ventilation support for all patients requiring respiratory support so that patients could be diagnosed when convenient. Such an approach, if patient-specific, would allow early action in a consistent framework that does not currently exist in the field. These results thus also clearly show the need for patient-specific MV that can evolve as dynamically as the patient in the first $24-48 \mathrm{~h}$.

\section{Summary}

Mechanical ventilation management must carefully balance a diverse range of different ventilator settings. Insufficient or excessive support results in potential harm to patients, prolonging their dependency on MV. This issue is exacerbated by inter-patient variability in response across cohorts, as well as by intra-patient variability in the evolution of condition. There is thus a strong need for optimal titration mechanisms that are patientspecific, specific to disease state, and can evolve dynamically, in real-time in response to patient condition.

\section{MV strategies and clinical trials}

There have been numerous ventilation strategies aimed at improving the quality of MV and patient outcomes [124]. Please refer to a recent review of the clinical advances for treatment of ARDS [1].

\section{Lung recruitment strategies: recruitment manoeuvres}

Recruitment as defined by Fan et al. [113], is the "dynamic process of reopening unstable airless alveoli through an intentional transient increase in transpulmonary pressure". Recruitment manoeuvres (RM) have shown to promote alveolar recruitment, increase end-expiratory volume, improve gas exchange, and attenuate VILI by preventing atelectrauma [113]. The tidal cycle during a RM shifts to where cyclic derecruitment is less likely to occur given that PEEP is greater than the closing pressure of the majority of alveoli. Early in the disease, atelectasis is reversible and the lung may be easily recruitable without negative side effects [125].

By transiently increasing pressure in the lung, collapsed or non-aerated alveoli have time to open and recruit. Alveolar recruitment increases the aerated lung volume aiding gas exchange and perfusion. The clinical benefits of RMs, particularly early in care, are numerous. However, the efficacy of RMs also degrade over time as the lung settles into a collapsed state and is thus again, more difficult to recruit [39, 126].

Evidence also suggests that high pressure RMs may overinflate parts of the heterogeneous ARDS or respiratory failure lung [127], and temporarily cause circulatory depression [128]. The links between respiratory failure severity, recruitability and other outcome measurements thus require further investigation and are not standardised, largely as a result of not being able to directly determine their impact on lung condition as they are conducted.

Rose et al. [3] described how effective RMs are difficult to conduct due to the heterogeneity of each patient and their response to increases of pressure. Specifically, for a 
given RM, some may over-distend and others fail to recruit [129], as lung elastance, the patient-specific response to pressure and volume varies. Thus, different types of RMs have been studied with inspiratory pressures anywhere between 30 and $60 \mathrm{cmH}_{2} \mathrm{O}$ [19]. Sustained inflations or breath holding sessions for up to $40 \mathrm{~s}$, intermittent sighs with high pressure or volume, and incremental increases in PEEP and/or PIP are also common types of RM. The goal in each case is to manage lung pressure to recruit more lung units without damaging others.

However, trials testing RMs have failed to produce consistent results and the best recruitment method is yet to be confirmed [113, 130]. Equally, some researchers have reported that not all patients benefit from an RM [17] or have any recruitable lung volume [121]. One recent meta-analysis [131] identified only 10 RCTs evaluating RMs and concluded that RMs decrease ICU mortality without increasing risk of barotrauma but found no effect on hospital or 28-day mortality. A second meta-analysis [132] reported a reduction in mortality pooling 6 RCTs as well as improved oxygenation and fewer rescue therapies. The authors of both meta-analyses noted the drastic differences between study designs and the prevalence of co-interventions (which together resemble the open lung approach) in the majority of the trials that may have confounded assessment of the effect of RMs. Thus, there remains a lack of confirmation of the long-term management, adverse effects, and generality of these findings in non-selected populations, further indicating a need for a patient-specific rather than cohort-specific, approach. Please refer to this recent review, and meta-analysis, of RMs [132].

\section{Setting MV using maximum compliance, inflection points}

Static compliance has been reported to change significantly with both tidal volume and PEEP [133-136]. The local maxima of compliance at a patient-specific PEEP was noted to be dependent on the ventilated tidal volume and explained in terms of position on the static pressure-volume (PV) curve [133-136]. In general, higher tidal volumes reduce the PEEP of maximum compliance [133-136], and equally, higher PEEP at a fixed tidal volume can have a similar effect [105].

The gold-standard approach to obtain a static PV curve is the super syringe method that quasi-statically fills the lung before emptying it in a controlled stepwise manner allowing equilibrium in between each step. The points are connected to form the sigmoidal static PV curve. The produced loop can be used to optimise PEEP and tidal volume. Specifically, PEEP can be set in between the lower inflection point (LIP) and upper inflection point (UIP) of the static PV curve.

The super syringe method is clinically cumbersome and high workload for clinical staff, as it requires detachment from the ventilator [137, 138] for up to $15 \mathrm{~min}$ [24]. Static PV curves can be obtained directly from some modern ventilators, but require the patients to be sedated and thus are still a significant interruption to care [24]. Hence, these curves are not typically or regularly assessed for clinical use.

Stahl et al. [139] described the potential in monitoring dynamic respiratory mechanics over incremental PEEP, such as a staircase RM, to estimate both mechanics and recruitment simultaneously. They reported that dynamic respiratory mechanics could be used as a diagnostic tool and would be more appropriate than using static mechanics. Comparing static and dynamic compliance, Stahl et al. reported that dynamic compliance 
was less than static compliance, but the difference was dependent on alveolar pressure [139].

Overall, static compliance neglects airway resistance and misrepresents lung dynamics by assuming a static or quasi-static condition, when regular MV breathing is dynamic. Monitoring dynamic compliance results in smaller compliance (higher elastance) values, indicating the significance of dynamic effects. It is possible to track breath-to-breath dynamic compliance (or elastance) over incremental PEEP [140, 141]. Thus, tracking dynamic compliance or elastance as a surrogate of lung condition can be used to quantify recruitment and guide care [24].

Of note, the use of the term static compliance or dynamic compliance are interchanged between studies [142]. Definitions in medical texts [44, 57], may be different from other studies $[129,139,143]$. Thus, it is important to be clear on the concept and application of each definition and method, to avoid misinterpretation of these findings.

\section{Lung protective strategies}

As a result of the difficult trade-offs between benefit and risk of MV, the goals of MV have changed over the last two decades. In particular, from specifying oxygenation goals, to a more cautious approach focusing on minimising VILI, while maintaining acceptable ventilation [101]. Avoiding atelectasis and overdistention of alveoli can attenuate alveolar and systematic inflammatory responses [22] and should translate into a measureable improvement in ARDS/ALI patient outcomes [2]. Hence, protection or risk mitigation has become a primary treatment endpoint.

A protective ventilation strategy is one aiming to minimise VILI and find a balance between oxygenation and $\mathrm{CO}_{2}$ elimination targets. Rose et al. [3] described the "mortality reducing effect of lung protective ventilation using low tidal volumes and pressure limitation" to prevent alveolar collapse or overdistention in ARDS patients. The study also suggested that these strategies might also be beneficial in patients with normal lungs. The following sections summarise several lung protective strategies examined.

\section{The ARDS network trial}

The ARDSNet strategy aims to minimise distension-induced lung injury, while maintaining acceptable oxygenation, by ventilating with small tidal volumes $(\leq 6 \mathrm{~mL} / \mathrm{kg})$ and plateau pressures lower than $30 \mathrm{cmH}_{2} \mathrm{O}$ [26]. The ARDSNet trial showed that lower tidal volumes $(6.2 \pm 0.8 \mathrm{~mL} / \mathrm{kg})$ are better than higher $(11.8 \pm 0.8 \mathrm{~mL} / \mathrm{kg})$. This low $\mathrm{V}_{\mathrm{t}}$ strategy uses tables of fixed combinations of $\mathrm{FiO}_{2}$ and PEEP that are periodically adjusted to maintain oxygenation goals [26]. ARDSNet is easy to follow, but relies on the relationship between $\mathrm{PaO}_{2}$ and $\mathrm{FiO}_{2}$ being generic to all patients at all times as their condition evolves.

However, the physiological rationale and the 'one size fits all' lack of individuality in care has been questioned [26]. The ARDSNet protocol may also be associated with increased atelectasis due to the low PEEP used and lack of RMs [26]. Thus, to avoid VILI by minimising lung strain and further improving care, the ideal tidal volume should be monitored in a patient-specific breath-by-breath or high time resolution approach similar to PEEP [24]. 


\section{The open lung approach}

The open lung approach (OLA) aims to open and maintain lung recruitment [1]. It also reduces dynamic strain [26]. RMs are used to open up the lung and PEEP is titrated to gas exchange or respiratory variables to maintain recruitment, avoiding cyclic collapse/re-opening [26].

Cohort based $\mathrm{OLA}$ approaches using $\mathrm{PEEP}-\mathrm{FiO}_{2}$ tables or oxygen saturation goals Three significant, early clinical trials of OLA strategies are ALVEOLI [8], LOVS [10], and EXPRESS [11]. ALVEOLI used two predetermined PEEP-FiO ${ }_{2}$ tables to ensure $\mathrm{SpO}_{2}$ was within acceptable limits of 88-95\% [8]. The lower PEEP group represented clinical consensus in 1995, whereas the higher PEEP group reflected the beneficial results of Amato et al. [7]. ALVEOLI used a target $V_{t}$ of $6 \mathrm{~mL} / \mathrm{kg}$ predicted body weight with PIP limited to $30 \mathrm{cmH}_{2} \mathrm{O}$ or less. LOVS [10] also utilised PEEP-FiO ${ }_{2}$ tables with $\mathrm{V}_{\mathrm{t}}$ of $6 \mathrm{~mL} /$ $\mathrm{kg}$, but conducted a $40 \mathrm{~s}$ breath-hold at $40 \mathrm{~cm} \mathrm{H}_{2} \mathrm{O}$ with $\mathrm{FiO}_{2}$ of 1.0 and thus allowed PIP up to $40 \mathrm{cmH}_{2} \mathrm{O}$. EXPRESS [11] took a different approach by adjusting $\mathrm{FiO}_{2}$ to maintain oxygenation goals for the participants in the 'minimal distension' control group. PEEP and PIP were kept as low as possible without dropping out of an acceptable oxygenation range. Within the increased recruitment group, PEEP was kept as high as possible preventing PIP rising above $30 \mathrm{cmH}_{2} \mathrm{O}$ regardless of the effect on oxygenation.

None of these three large multi-centre trials conclusively reported any benefit of the OLA or higher PEEP ventilation. However, EXPRESS did report a significant improvement in ventilator free-days (median [IQR]: 7 [0-19] vs 3 [0-17], $\mathrm{p}=0.04$ ). Although the primary outcome of mortality failed to reach significance, benefits including higher compliance values, improved oxygenation $[8,11]$, and reduced rates of, and death from, refractory hypoxemia [10], were achieved.

OLA approaches using PEEP based on static pressure-volume curves An early, small trial by Amato et al. [7] reported a benefit from higher PEEP ventilation above the LIP on a PV curve compared to standard ventilation. Mortality was reduced from 71 to $38 \%$ and rates of barotrauma were greatly reduced $(n=53, p<0.001)$. Villar et al. [9] conducted a similar trial, setting PEEP $2 \mathrm{cmH}_{2} \mathrm{O}$ higher than the LIP and reported significant improvements in ICU and hospital mortality, ventilator free days, and organ failures $(n=95)$. However, Oba et al. [12] argued that the static pressure-volume curve may not be the best way to select optimal PEEP for an OLA.

OLA approaches using PEEP based on dynamic compliance/elastance Spieth et al. [26] conducted an animal trial involving pigs with surfactant washout induced ARDS, randomised into either the standard ARDSNet protocol $\left(\mathrm{PEEP}=12 \mathrm{cmH}_{2} \mathrm{O}\right)$ or an open lung approach (OLA) with PEEP set to minimal respiratory elastance. PEEP and mean airway pressure were higher in the OLA. OLA was associated with improved oxygenation after $6 \mathrm{~h}$ and redistributed pulmonary perfusion, but with more alveolar overdistension, while ARDSNet was associated with more intra-alveolar haemorrhage. Inflammatory mediators and markers of lung parenchymal stress did not differ significantly. Better redistribution of pulmonary blood flow in the OLA approach may contribute to better ventilationperfusion matching and the reported improved oxygenation. 
Another, more recent, animal study by Santos et al. [144] compared the pulmonary vascular mechanics of three groups each with PEEP set based on the maximal compliance PEEP, (1) hyperinflation $=6 \mathrm{cmH}_{2} \mathrm{O}$ above, (2) $\mathrm{OLA}=2 \mathrm{cmH}_{2} \mathrm{O}$ above, and (3) collapse $=6 \mathrm{cmH}_{2} \mathrm{O}$ below. The OLA group displayed the lowest pulmonary artery resistance, effective arterial elastance, and reflection coefficient. The authors concluded that OLA was the best setting. Therefore, a patient-specific OLA strategy providing PEEP corresponding to minimal elastance (or maximal compliance) is beneficial in pigs, but remains untested against clinical outcomes in a randomized controlled trial in humans.

There are two recent studies that have shown promising results of the OLA. First, a multicenter RCT, by the Open Lung Approach Network [145], screen 1874 patients under 'standardized ventilator settings' $\left(\mathrm{FiO}_{2} \geq 0.5, \mathrm{PEEP} \geq 10 \mathrm{cmH}_{2} \mathrm{O}\right)$ and included patients with ARDS (P/F ratio $\leq 200 \mathrm{mmHg}$ ) into either a control ARDSNet group $(\mathrm{n}=101$, PEEP set by the ARDSNet protocol [5]) or a OLA group $(\mathrm{n}=99$, PEEP $=$ PEEP at maximal dynamic compliance). Both airway driving pressure and $\mathrm{P} / \mathrm{F}$ ratio improved significantly at 24, 48, and $72 \mathrm{~h}$ for the OLA group as compared to ARDSNet group. Although the study was statistically underpowered to significantly show reductions in mortality, a non-significant trend of lower mortality was observed (60 day: $29 \%$ vs $33 \%$, $\mathrm{p}=0.18$; ICU $25 \%$ vs $30 \%, \mathrm{p}=0.53$ ). Ventilator-free days were similar in both groups ( 8 $[0-20]$ vs $7[0-20], p=0.53)$. The Open Lung Approach Network concluded that OLA improves oxygenation and driving pressure without detrimental effects, which supports a larger multicenter OLA trial. The careful design of performing patient screening under standardized conditions ensures that inclusion is not biased by the current ventilator settings that are known to affect P/F ratio and subsequent ARDS diagnosis [121, 122].

The second study also examined the effect of OLA but instead in a cohort of major abdominal surgery patients [146]. Patients were assessed after a 30-min period of standardized ventilation $\left(\mathrm{V}_{\mathrm{t}}=6 \mathrm{~mL} / \mathrm{kg}, \mathrm{PEEP}=5 \mathrm{cmH}_{2} \mathrm{O}\right)$ and subjected to a $\mathrm{RM}$ after which each patient was randomized into either a control group $\left(\mathrm{n}=18, \mathrm{PEEP}=5 \mathrm{cmH}_{2} \mathrm{O}\right)$, or an individualized open-lung PEEP group $(n=18$, PEEP $=$ PEEP at maximal dynamic compliance). Compared to the condition prior to the RM, the OLA group displayed an improvement in both: (1) an increase in compliance and (2) a decrease in driving pressure, whereas the control group did not. Despite being performed in anesthetized healthy individuals, opposed to ARDS patients, this study further validates the intuition behind the OLA, RMs and individualized PEEP settings.

Overall, different studies of OLA strategies have shown modest clinical benefits. However, improvements in primary patient outcomes have not yet been fully established by large multi-centre trials $[7-11,145]$. Again, the lack of a patient-specific approach is a potential limiting factor that could impede some of these studies. The more recent OLA results [145-147] point towards a patient-specific compliance/elastance as a means of obtaining the best benefits of an OLA approach.

\section{Variable ventilation strategies}

Healthy physiological systems exhibit a natural variability that leads to greater flexibility and more robust function compared to diseased systems. In contrast, a low variability 
breathing pattern may be observed in MV patients who failed to wean from MV. Thus, it has been proposed to reintroduce variability to replicate this behaviour [148].

Variable controlled ventilation has been associated with improved oxygenation, a reduction in mean peak airway pressure, as well as improved pulmonary function in several animal studies [149-153]. The best results occur when tidal volume variability matches the variability in healthy subjects [154]. The mechanisms responsible may include recruitment, surfactant release and improved volume/flow matching because of the redistribution of pulmonary blood flow [151, 152]. It is hypothesized that variable tidal volumes improve pulmonary function by replicating natural variability.

Neurally adjusted ventilation assist mode (NAVA) [155], is an assist ventilation mode that uses patient diaphragm electrical activity, Eadi, to trigger and cycle off the ventilator support. It also uniquely delivers airway pressure in proportion to this measured Eadi, matching ventilator support with patient's demand. NAVA was found to improve patient-ventilator interaction, reducing the number of asynchrony events [156], as well as increasing respiratory variability in $V t$ and flow related variables [157]. Studies on NAVA have reported on impact to the patients [158-160], and an optimal titration method [161, 162]. Thus, the benefits of this approach are potentially more substantial for patients ventilated for long durations. However, similar to other ventilation strategies, there is also limited guideline is setting the appropriate NAVA level [161-163] of pressure support, so its use is affected by this difficulty and its added cost.

\section{High frequency oscillatory ventilation (HFOV) and airway pressure release ventilation (APRV)}

In both these approaches, a relatively high mean airway pressure, referred to as 'continuous distending pressure' in HFOV or ' $\mathrm{P}_{\text {high }}$ ' in APRV, is used to maintain a healthy to high end-expiratory lung volume and adequate oxygenation levels. Both methods promote alveolar recruitment and maintenance due to the continuously elevated pressure within the lung, and minimising atelectasis as the minimum pressure is relatively high. Recruitment not only depends on the pressure in the lung, but also the duration that pressure is held, where elevated pressures for a relatively long time can assist with opening more stubborn, stiffer alveoli.

HFOV ventilation uses rapid application of small tidal volume breaths with a large mean airway pressure to ensure adequate oxygenation [101, 164, 165]. However, due to the small tidal volume breaths, the patient's lung has a large proportion of dead space and reduced alveolar minute ventilation with less $\mathrm{CO}_{2}$ clearance. The majority of HFOV studies treated neonatal patients and reported small reductions in chronic lung disease [101]. Recent studies to compare HFOV with conventional MV have reported promising physiological and inflammatory results $[101,165]$ but others have reported no effect on patient outcomes [166]. Moreover, recent guidelines [28] considering six RCTs strongly recommend that HFOV should not be routinely used in moderate-severe ARDS patients. The deleterious effects of HFOV, observed in some studies, may be attributed to higher airway pressures causing negative hemodynamic consequences [1].

APRV is similar to HFOV, but includes brief periods where the pressure is dropped to release air from the lungs and eliminate $\mathrm{CO}_{2}$. These pressure releases must be kept brief to prevent the pressure dropping to a point where the alveoli may start to collapse. 
The pressure releases are crucial to eliminate respired $\mathrm{CO}_{2}$ out of the lung. Thus, patients that have hypercapnia should be ventilated with more frequent or longer duration releases, whereas patients that have hypoxemia require fewer and shorter releases requiring patient-specific adjustment [167]. The balancing point has yet to be determined in groups where both hypoxemia and hypercapnia occur together. APRV facilitates spontaneous breathing and has been associated with progressive recruitment [168], improved oxygenation [52], reduced peak airway pressures [52, 168], and improved volume/flow matching [169] however, a recent review [170] described 'tremendous variation' in published settings referred to as APRV limiting definitive conclusions and clinical application.

Although HFOV and APRV are protective strategies operating on similar principles, their applications are quite different. HFOV requires sedation and has not been conclusively proven in adult human trials $[1,28]$. APRV on the other hand, has been shown to be clinically beneficial in spontaneously breathing patients, but is still relatively new in practice. Neither is necessarily patient-specific in its application, thus still relying on clinical judgement to find optimal settings, and neither has reached a state of regular use or wide uptake.

\section{Summary}

In summary, it is currently clear that no general, "one size fits all" cohort-specific protocol is broadly successful. It is equally clear that respiratory failure patients requiring mechanical ventilation are highly variable and there is a need to manage mechanical ventilation strategy based on patient-specific needs, rather than per cohort. Hence, it is very important to have the means to assess the dynamic changes in patient-specific respiratory disease state regularly in clinical real-time without additional invasive measurements or interruptions to care. Different strategies, each based upon different intuition on how ventilation can be improved, have been presented. To summarize their commonalities and differences, Table 1 briefly summarizes the aims of recent research, the driving intuition behind how each strategy intends to address the various problems facing MV in clinical practice and the limitations of the strategy. One trend apparent in Table 1 is that many recent research areas focus on the related problem of inter- and intra-patient variability with the intention that personalized ventilation will avoid VILI and enable application to any patient requiring MV without diagnosis of ARDS.

\section{The path forward for mechanical ventilation and the role of engineers}

Mechanical ventilation is straightforward in principle. However, it is complex in implementation, due partly to heterogeneity of disease and partly to the individual's response to treatment. There thus remains a need to improve MV management and engineers can play an important role in both research and development of those next-generation solutions.

\section{Managing inter- and intra-patient variability}

Due to inter- and intra-patient heterogeneity, ventilating respiratory failure patients with generalised approaches will not cater for patient-specific needs. What is needed, is the ability to accurately assess lung condition non-invasively and in real-time with no 

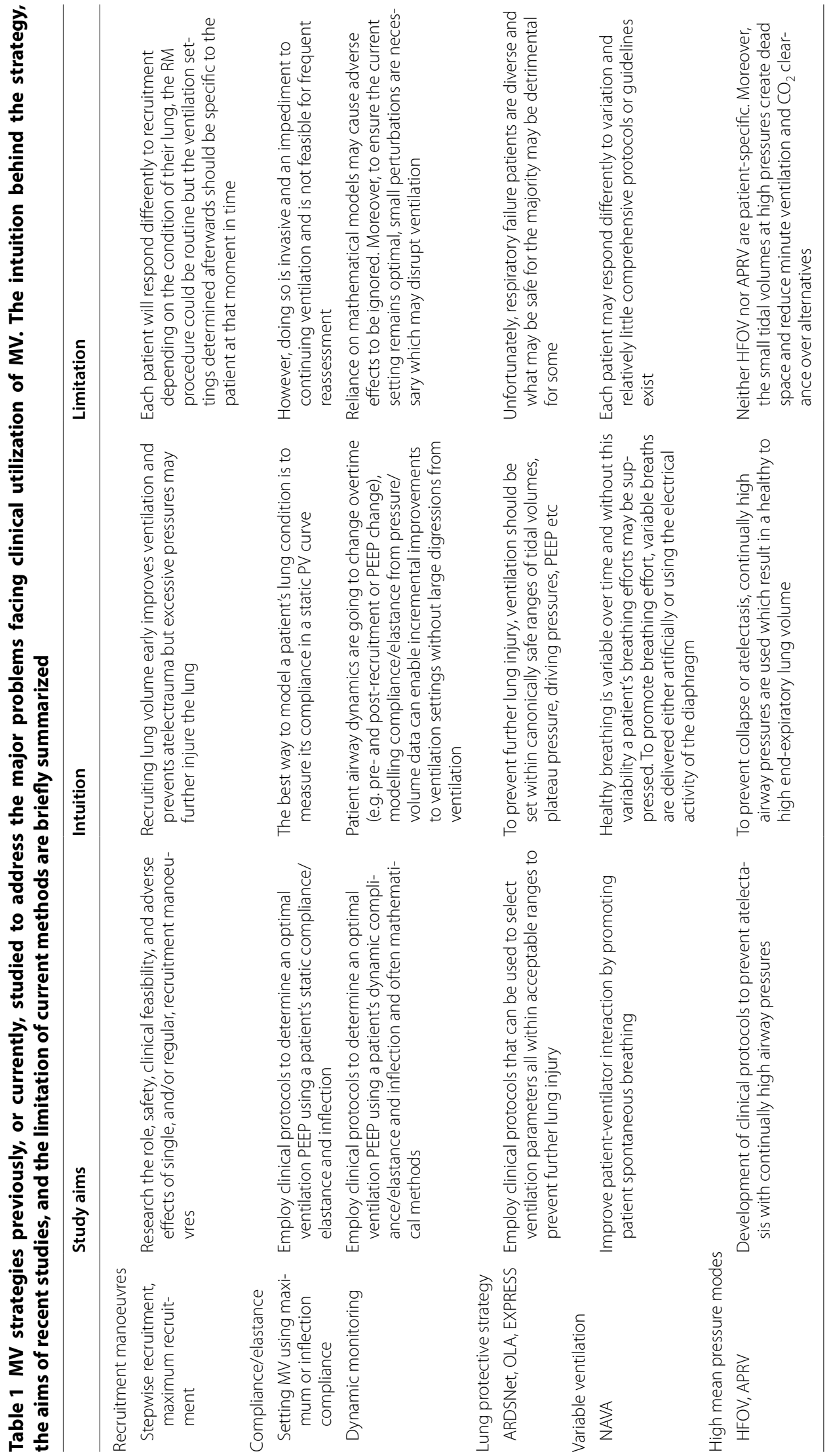
interruption to ventilation. In addition, the lung condition of an ARDS or respiratory failure patient can change dramatically over the first $24 \mathrm{~h}$ of ventilation [171, 172].

In particular, lung condition improves with effective MV, which in turn, can significantly alter the patient's need for subsequent ventilation [60]. Thus, instead of selecting PEEP once at the start of MV [7, 9], or only occasionally, ventilation settings should be constantly titrated, either breath-to-breath or very regularly. These changes should occur in clinical real-time to evolve with the patient and reflect their current condition, preferably in an automated fashion that is not burdensome to care givers [173]. However, this outcome requires automated data acquisition, and computational modelling and methods, to provide to necessary monitoring and decision support. More specifically, automated ventilation strategies that cater for individual, patient-specific needs can potentially be realised with the advancement of engineering technologies and model-based methods.

\section{Improving technologies and model-based methods}

Lung imaging technologies

Lung imaging is one means of providing regular monitoring of lung condition. Various imaging technologies have emerged to help clinicians diagnose patient condition. These technologies, such as EIT [174], ultrasound [175-177], or low dose CT [178], provide potential means to measure lung condition. These imaging techniques are comparatively non-invasive, and can be applied frequently in MV patients to potentially improve MV delivery. However, there is significant need for improvement.

For example, EIT operates regionally, capturing lung images representing a 5-10 cm cross-section relative to its position [70]. Thus, application of EIT is limited to regional lung recruitment monitoring and extrapolation to global measures of ventilation. Expanding EIT to multi-slice or complete lung imaging would require a significant increase in the number of required sensors, and thus the required computing resource for signal processing and image reconstruction, all of which may limit real-time analyses. Significant research is required to optimise the architecture and implementation of a real-time, complete lung EIT system, from computational methods to speed solution to more advanced and accurate inverse models.

In addition, EIT, CT or ultrasound images do not provide absolute and objective measurement of lung condition. Specialised clinicians are required to interpret images, diagnose and recommend treatment. In addition, differences in clinician background and experience may potentially lead to inconsistent evaluation, yielding errors in decisionmaking and treatment recommendations that may harm patients. Further research is required in these existing imaging technologies, including improving image quality, and providing more objective information that does not rely on clinical experience and evaluation for robust clinical decision-making which, if successful, will ultimately improve patient care.

\section{Research in novel ventilation modes}

New ventilation modes such as NAVA [179], variable pressure support [151], automatic protective ventilation [173], proportional assist ventilation [180] and other nonconventional techniques [181] were developed as means to improve MV treatment. 
Unfortunately, the application of these MV modes remains limited due to a lack of clinical guidelines, based, in turn, on lack of methods to monitor and optimise their use for specific patients who might benefit. In addition, there is currently a lack of evidence, supported by clinical studies with sufficiently large patient cohorts, to justify application of these modern MV modes into daily clinical practice, in turn limiting the data available to develop the engineering tools and methods to optimise their use.

Fortunately, these ventilation modes are becoming increasingly popular in engineering signal processing research. In particular, clinically useful decision support systems are being developed to help clinicians interpret patient condition, as well as guide clinicians to better manage MV. For example, Moorhead et al. studied potential models and metrics in setting NAVA level [157], Sinderby et al. have developed a neural index to quantify the quality of patient-ventilation interaction during NAVA [182], and Pomprapa et al. have investigated lung protective ventilation with the use of EIT [183]. Engineering research was crucial for the development of these MV modes and will continue to be critical to their validation and implementation.

\section{Model-based methods}

One prospective topic of MV engineering research relates to applying model-based algorithms in conjunction with specialised clinical protocols. Mathematical modelling of the respiratory system, and its effects on the cardiovascular system, allow estimates of a patient's response to changes in their treatment, which can allow virtual trials [184] or provide recommendations to a physician as part of a clinical decision support system [185].

Mathematical modelling Model-based research can include development of mathematical models and validating model relevance, as well as identification of parameters, conducting decision metric studies, and clinical trial development. All these outcomes also lead toward validating the efficacy and generalizability of physiological models at the bedside.

One popular model-based research area is mathematical modelling of lung physiology. These models, ranging from simple to complex forms [186-190], describe lung physiology to help researchers better understand lung conditions. Some models can also be used to assess real-time patient-specific condition [25, 105, 191-193], recruitment status [24, 191, 193, 194], and patient-specific response to MV [191, 193, 195]. Importantly, they all offer insight into patient-specific condition that is not available via typical static surrogate estimates $[189,196]$, and, they can be estimated breath-to-breath, and monitored as a surrogate of patient condition without interruption. As a result, they have the potential to be applied in MV management [105, 191, 193, 197]. Reviews of lung modelling exist $[198,199]$ but unfortunately, few focus on clinical utility, and none, that we are aware of, outside our group [24].

Validation of model-based methods Mathematical models are typically developed and validated with data derived from animal or human studies. An extension of these 'insilico' simulations is the concept of virtual patients: a dataset of patients, including both ventilation and physiologic data, that can be used to test and validate mathematical mod- 
els and their utility to measure disease and provide recommendations. A recent review on model-based therapeutics appeared, from our group in this journal, which covered modelling of virtual patients and their validation, which is a major step towards using models in clinical application to guide care [184].

The natural next step beyond simulation, or virtual patient, based studies are prospective studies where current ventilation settings and physiologic measurements are used in a feedback loop to influence further MV therapy. Several groups have developed methods to provide 'automatic' MV, using physiologic measurements with standard protocols or closed-loop feedback systems, to fine-tune ventilator settings during MV however, these works are currently limited to animal studies [183, 200]. Similarly, non-modelbased studies have assessed the feasibility of recommending optimal PEEP in small studies using EIT for example [201]. These studies have shown the feasibility of closing the feedback loop to provide near autonomous MV within prescribed parameters.

Personalizing MV to account for inter- and intra-patient variability using mathematical modelling has been described in simulations [185], retrospective comparison studies [202] or prospective feasibility/pilot studies aiming to provide recommendations $[105,203,204]$. One particular group has recently commercialized their physiological modelling research into a decision support system however, their published results are also limited to small, feasibility studies [205, 206]. To our knowledge, no large, outcome-focused trial assessing the clinical utility and efficacy of model-based MV has been published. Thus, despite the potential of model-based methods to guide care, as seen in other areas [184], there are yet to be any clinical trials comparing outcomes of a model-based MV intervention, against standard practice, barring the ongoing CURE ${ }^{1}$ trial [207], which is recruiting slowly at this time, and the recently initiated $\mathrm{CARE}^{2}$ trial in Malaysia (unpublished).

Next steps in model-based MV Implementation of any automatic or prescriptive MV system, model-based or otherwise, must consider the ramifications of MV in a patientspecific manner. Some ventilated patients develop asynchrony, expiratory flow limitation or negative hemodynamic consequences during MV. Asynchronous (or dyssynchronous) breathing occurs when the MV is mis-matched with the patient's breathing efforts. Improved signal processing may improve robust application of model-based methods [208]. Moreover, improved modelling, for example adding EIT signals, may improve alignment between the ventilator and the patient by modelling patient efforts. Expiratory flow limitation (EFL) is believed to occur when smaller airways constrict during expiration, isolating areas of residual high pressure and thus limiting gas exchange [209]. Appropriate MV settings, especially PEEP, for patients with EFL can be very different than typical care; improved modelling could aid detection and PEEP titration to deliver appropriate patient-specific care [209]. MV intended to be protective can negatively affect hemodynamics in ARDS patients [1]. Improved modelling of the cardiopulmonary system could yield insights into the hemodynamic effects of MV and mitigate the consequences that have lead to early stopping of some clinical trials. Biomedical engineers have a valuable

\footnotetext{
${ }^{1}$ https://www.anzctr.org.au/Trial/Registration/TrialReview.aspx?id=366838.

${ }^{2}$ https://www.anzctr.org.au/Trial/Registration/TrialReview.aspx?id=373157.
} 
opportunity to advance clinical practice by combining clinical study results and intuition with individualized modelling of a complex, interrelated biomedical system.

Overall, mathematical models can generate insight into pulmonary physiology and patient-specific ventilation and perfusion in response to ventilator settings. Equally, forecasting poor responses can prevent negative clinical outcomes, such as desaturation or lung collapse and thus further improve patient care at the individual level. There is thus an emerging capability for clinicians to titrate patient-specific care using such computational models developed in collaboration with engineers. Coupled with regular recruitment and other protective lung strategies, model-based treatment offers the opportunity for clinicians to provide patient-specific therapy in a consistent fashion. In essence, software services augment the ventilator hardware and ventilator modes to further monitor and optimise care.

Finally, model-based MV research is not without challenge. It is often hindered by the need of specialised clinical protocols [38, 210-213], results comparison and validation $[62,214,215]$, data quality, and model identification [190, 212, 216]. Ultimately, the need for large randomised controlled trials is a further limitation. As a result, to date, models have not yet been used to prospectively guide therapy directly in a larger setting [105, 197], although pilot trials have been conducted [25, 207, 217]. Hence, the need of engineering methods to improve mechanical ventilation management is imminent and it is paramount for engineers to understand clinical aspects of mechanical ventilation and potential advancement.

\section{Conclusion}

The overall review summarises the clinical state of the art in the research and application of MV in an engineering context. In general, existing MV management is general and describes a 'one size fits all' cohort-based approach that does not address the heterogeneity of the ventilated patient lung, nor the inter- and intra-patient variability critically ill patients exhibit. It is thus not able to deliver further improvements in clinical outcomes without a drastic change towards a patient-specific approach that exploits data captured non-invasively in real-time.

New technologies and model-based ventilation have been gaining ground in MV research. Model-based estimation enables the clinician to evaluate, otherwise unavailable, patient-specific lung condition, monitor patient evolution, and, once informed, select an optimal MV setting guided by a clinical protocol. Such a development provides an individualised, patient-specific or personalised 'one method fits all' approach that monitors every breath and guides therapy in real-time, including recruitment manoeuvre interventions and timing. This model-based approach in particular provides a means for engineers and clinicians to collaborate to create personalised next-generation solutions to this significant and costly health care problem, thus improving clinical ability to provide safe, effective MV beyond what is possible today. 
HFOV: high frequency oscillatory ventilation; ICU: intensive care unit; l:E: inspiration to expiration; LoMV: length of mechanical ventilation; LIP: lower inflection point; MV: mechanical ventilation; NAVA: neurally adjusted ventilation assist; $\mathrm{NIV}$ : non-invasive ventilation; OLA: open lung approach; $\mathrm{P} / \mathrm{F}: \mathrm{PaO}_{2} / \mathrm{FiO}_{2} ; \mathrm{PaO}_{2}$ : partial pressure of oxygen; $\mathrm{P}_{\text {aw }}$ : airway pressure; PEEP: positive end expiratory pressure; PIP: peak inspiratory pressure; $P_{\text {plat: }}$ plateau pressure; PV: pressure-volume; RM: recruitment manoeuvre; RR: respiratory rate; SAPS: simplified acute physiology score; SIMV: synchronized intermittent mandatory ventilation; SOFA: sequential organ failure assessment score; $\mathrm{SpO}_{2}$ : peripheral capillary oxygen saturation; UIP: upper inflection point; VFD: ventilation free days; VILI: ventilator/ventilation induced lung injury; $V_{t}$ : tidal volume.

\section{Authors' contributions}

VJM and YSC prepared the manuscript. All authors had input in writing and revising the manuscript. All authors read and approved the final manuscript.

\section{Author details}

${ }^{1}$ Department of Population Health, NYU Langone Health, New York, NY, USA. ${ }^{2}$ School of Engineering, Monash University Malaysia, Subang Jaya, Malaysia. ${ }^{3}$ Department of Intensive Care, Christchurch Hospital, Christchurch, New Zealand.

${ }^{4}$ Centre for Bioengineering, University of Canterbury, Christchurch, New Zealand.

\section{Acknowledgements}

Preparation of this article began while Vincent J. Major was affiliated with the Centre for Bioengineering, University of Canterbury.

Competing interests

The authors declare that they have no competing interests.

\section{Availability of data and materials}

Not applicable.

\section{Consent for publication}

Not applicable.

\section{Ethics approval and consent to participate}

Not applicable.

\section{Funding}

The authors wish to thank the New Zealand Health Research Council (HRC) (Ref: 13/213) and Malaysia Ministry of Higher Education (MOHE) Fundamental Research Grant Scheme (FRGS) (Ref: FRGS/1/2016/TK03/MUSM/03/2) for supporting this research.

\section{Publisher's Note}

Springer Nature remains neutral with regard to jurisdictional claims in published maps and institutional affiliations.

\section{Received: 29 June 2017 Accepted: 1 November 2018}

Published online: 12 November 2018

\section{References}

1. Fan E, Brodie D, Slutsky AS. Acute respiratory distress syndrome: advances in diagnosis and treatment. JAMA. 2018;319(7):698-710.

2. Slutsky AS. Lung injury caused by mechanical ventilation. Chest. 1999;116(suppl 1):9S-15S.

3. Rose L. Clinical application of ventilator modes: ventilatory strategies for lung protection. Aust Crit Care. 2010;23(2):71-80

4. Mertens M, Tabuchi A, Meissner S, Krueger A, Schirrmann K, Kertzscher U, et al. Alveolar dynamics in acute lung injury: heterogeneous distension rather than cyclic opening and collapse. Crit Care Med. 2009;37(9):2604-11.

5. The Acute Respiratory Distress Syndrome Network. Ventilation with lower tidal volumes as compared with traditional tidal volumes for acute lung injury and the acute respiratory distress syndrome. N Engl J Med. 2000;342(18):1301-8.

6. Girard TD, Bernard GR. Mechanical ventilation in ARDS. Chest. 2007;131(3):921-9.

7. Amato MBP, Barbas CSV, Medeiros DM, Magaldi RB, Schettino GP, Lorenzi-Filho G, et al. Effect of a protective-ventilation strategy on mortality in the acute respiratory distress syndrome. N Engl J Med. 1998;338(6):347-54.

8. Brower RG, Lanken PN, MacIntyre N, Matthay MA, Morris A, Ancukiewicz M, et al. Higher versus lower positive endexpiratory pressures in patients with the acute respiratory distress syndrome. N Engl J Med. 2004;351 (4):327-36.

9. Villar J, Kacmarek R, Perez-Mendez L, Aguirre-Jaime A. A high positive end-expiratory pressure, low tidal volume ventilatory strategy improves outcome in persistent acute respiratory distress syndrome: a randomized, controlled trial. Crit Care Med. 2006;34(5):1311-8.

10. Meade MO, Cook DJ, Guyatt GH, Slutsky AS, Arabi YM, Cooper DJ, et al. Ventilation strategy using low tidal volumes, recruitment maneuvers, and high positive end-expiratory pressure for acute lung injury and acute respiratory distress syndrome: a randomized controlled trial. JAMA. 2008;299(6):637-45.

11. Mercat A, Richard J-CM, Vielle B, Jaber S, Osman D, Diehl J-L, et al. Positive end-expiratory pressure setting in adults with acute lung injury and acute respiratory distress syndrome: a randomized controlled trial. JAMA. 2008;299(6):646-55. 
12. Oba Y, Thameem DM, Zaza T. High levels of PEEP may improve survival in acute respiratory distress syndrome: a meta-analysis. Respir Med. 2009;103(8):1174-81.

13. Briel M, Meade M, Mercat A, Brower RG, Talmor D, Walter SD, et al. Higher vs lower positive end-expiratory pressure in patients with acute lung injury and acute respiratory distress syndrome: systematic review and meta-analysis. JAMA. 2010;303(9):865-73.

14. Bos LD, Martin-Loeches I, Schultz MJ. ARDS: challenges in patient care and frontiers in research. Eur Respir Rev. 2018;27(147):170107.

15. Hickling KG, Henderson SJ, Jackson R. Low mortality associated with low volume pressure limited ventilation with permissive hypercapnia in severe adult respiratory distress syndrome. Intensive Care Med. 1990;16:372-7.

16. Gattinoni L, Carlesso E, Brazzi L, Caironi P. Positive end-expiratory pressure. Curr Opin Crit Care. 2010;16(1):39-44.

17. Guerin C. The preventive role of higher PEEP in trating severely hypoxemic ARDS. Minerva Anestesiol. 2011;77(8):835-45.

18. Malbouisson LM, Muller J-C, Constantin J-M, Lu QIN, Puybasset L, Rouby J-J, et al. Computed tomography assessment of positive end-expiratory pressure-induced alveolar recruitment in patients with acute respiratory distress syndrome. Am J Respir Crit Care Med. 2001;163(6):1444-50.

19. Borges JB, Okamoto VN, Matos GF, Caramez MP, Arantes PR, Barros F, et al. Reversibility of lung collapse and hypoxemia in early acute respiratory distress syndrome. Am J Respir Crit Care Med. 2006;174:268-78.

20. de Matos G, Stanzani F, Passos R, Fontana M, Albaladejo R, Caserta R, et al. How large is the lung recruitability in early acute respiratory distress syndrome: a prospective case series of patients monitored by computed tomography. Crit Care. 2012;16(1):R4.

21. Thammanomai A, Hamakawa H, Bartolák-Suki E, Suki B. Combined effects of ventilation mode and positive endexpiratory pressure on mechanics, gas exchange and the epithelium in mice with acute lung injury. PLoS ONE. 2013;8(1):e53934.

22. Rouby JJ, Lu Q, Goldstein I. Selecting the right level of positive end-expiratory pressure in patients with acute respiratory distress syndrome. Am J Respir Crit Care Med. 2002;165(8):1182-6.

23. Ranieri VM, Suter PM, Tortorella C, De Tullio R, Dayer JM, Brienza A, et al. Effect of mechanical ventilation on inflammatory mediators in patients with acute respiratory distress syndrome: a randomized controlled trial. JAMA. 1999;282:54-61

24. Sundaresan A, Chase JG. Positive end expiratory pressure in patients with acute respiratory distress syndromethe past, present and future. Biomed Signal Process Control. 2011;7(2):93-103.

25. Chiew YS, Pretty C, Redmond D, Shaw GM, Desaive T, Chase JG, editors. A better way to determine sample size to detect changes in length of mechanical ventilation? In: 35th international symposium on intensive care and emergency medicine; 2015 17-20 March; Brussels, Belgium. In Critical Care 19(Supple 1): 227.

26. Spieth PM, Güldner A, Carvalho AR, Kasper M, Pelosi P, Uhlig S, et al. Open lung approach vs acute respiratory distress syndrome network ventilation in experimental acute lung injury. BJA Br J Anaesth. 2011;107(3):388-97.

27. Talmor D, Sarge T, Malhotra A, O'Donnell CR, Ritz R, Lisbon A, et al. Mechanical ventilation guided by esophageal pressure in acute lung injury. N Engl J Med. 2008;359(20):2095-104.

28. Fan E, Sorbo LD, Goligher EC, Hodgson CL, Munshi L, Walkey AJ, et al. An Official American Thoracic Society/ European Society of Intensive Care Medicine/Society of Critical Care Medicine Clinical Practice Guideline: mechanical ventilation in adult patients with acute respiratory distress syndrome. Am J Respir Crit Care Med. 2017;195(9):1253-63.

29. Chao DC, Scheinhorn DJ. Barotrauma vs volutrauma. Chest J. 1996;109(4):1127-8.

30. Dreyfuss D, Saumon G. Ventilator-induced lung injury. Lessons from experimental studies. Am J Respir Crit Care Med. 1998:157(1):294-323.

31. Slutsky A. Mechanical ventilation. In: American College of Chest Physicians' Consensus Conference. Chest. 1993;104(6):1833-59.

32. Rachmale S, Li G, Wilson G, Malinchoc M, Gajic O. Practice of excessive FIO2 and effect on pulmonary outcomes in mechanically ventilated patients with acute lung injury. Respir Care. 2012;57(11):1887-93.

33. Jackson RM. Pulmonary oxygen toxicity. Chest. 1985;88(6):900-5.

34. Powers SR Jr, Mannal R, Neclerio M, English M, Marr C, Leather R, et al. Physiologic consequences of positive endexpiratory pressure (PEEP) ventilation. Ann Surg. 1973;178(3):265.

35. Gallagher TJ, Civetta JM, Kirby RR. Terminology update: optimal PEEP. Crit Care Med. 1978;6(5):323-6.

36. Petersen GW, Baier H. Incidence of pulmonary barotrauma in a medical ICU. Crit Care Med. 1983;1 1(2):67-9.

37. Parker JC, Hernandez LA, Peevy KJ. Mechanisms of ventilator-induced lung injury. Crit Care Med. 1993;21:131.

38. Barberis L, Manno E, Guérin C. Effect of end-inspiratory pause duration on plateau pressure in mechanically ventilated patients. Intensive Care Med. 2003;29(1):130-4.

39. Gattinoni L, Caironi P, Cressoni M, Chiumello D, Ranieri VM, Quintel M, et al. Lung recruitment in patients with the acute respiratory distress syndrome. N Engl J Med. 2006;354(17):1775-86.

40. Amato MB, Meade MO, Slutsky AS, Brochard L, Costa EL, Schoenfeld DA, et al. Driving pressure and survival in the acute respiratory distress syndrome. N Engl J Med. 2015;372(8):747-55.

41. Heinze H, Schaaf B, Grefer J, Klotz K, Eichler W. The accuracy of the oxygen washout technique for functional residual capacity assessment during spontaneous breathing. Anesth Analg. 2007;104(3):598-604.

42. Aoyama H, Pettenuzzo T, Aoyama K, Pinto R, Englesakis M, Fan E. Association of driving pressure with mortality among ventilated patients with acute respiratory distress syndrome: a systematic review and meta-analysis. Crit Care Med. 2018;46(2):300-6.

43. Mireles-Cabodevila E, Diaz-Guzman E, Heresi GA, Chatburn RL. Alternative modes of mechanical ventilation: a review for the hospitalist. Clevel Clin J Med. 2009;76(7):417-30.

44. Hasan A. Understanding mechanical ventilation: a practical handbook. 2nd ed. Berlin: Springer; 2010

45. Rabec C, Rodenstein D, Leger P, Rouault S, Perrin C, Gonzalez-Bermejo J. Ventilator modes and settings during non-invasive ventilation: effects on respiratory events and implications for their identification. Thorax. 2011;66(2):170. 
46. Brochard L. Mechanical ventilation: invasive versus noninvasive. Eur Respir J. 2003;22(47 suppl):31s-7s.

47. Elliott MW. Non-invasive ventilation for acute respiratory disease. Br Med Bull. 2004;72(1):83-97.

48. Peñuelas Ó, Frutos-Vivar F, Esteban A. Searching for the lost road of the non-invasive positive pressure ventilation in the acute respiratory distress syndrome. Eurasion J. Emerg. Med. 2017;16(3):90-1.

49. Agarwal R, Aggarwal AN, Gupta D. Role of noninvasive ventilation in acute lung injury/acute respiratory distress syndrome: a proportion meta-analysis. Respir Care. 2010;55(12):1653-60.

50. Bellani G, Laffey JG, Pham T, Madotto F, Fan E, Brochard L, et al. Noninvasive ventilation of patients with acute respiratory distress syndrome. Insights from the lung safe study. Am J Respir Crit Care Med. 2017;195(1):67-77.

51. Patel BK, Wolfe KS, Pohlman AS, Hall JB, Kress JP. Effect of noninvasive ventilation delivered by helmet vs face mask on the rate of endotracheal intubation in patients with acute respiratory distress syndrome: a randomized clinical trial. JAMA. 2016;315(22):2435-41.

52. Habashi NM. Other approaches to open-lung ventilation: airway pressure release ventilation. Crit Care Med. 2005;33:S228-40.

53. Guldager H, Nielsen SL, Carl P, Soerensen MB. A comparison of volume control and pressure-regulated volume control ventilation in acute respiratory failure. Crit Care. 1997;1(2):75-7.

54. Mellemgaard K. The alveolar-arterial oxygen difference: its size and components in normal man. Acta Physiol Scand. 1966;67(1):10-20.

55. Sorbini C, Grassi V, Solinas E, Muiesan G. Arterial oxygen tension in relation to age in healthy subjects. Respiration. 1968;25(1):3-13.

56. Kim J, Seo BS. How to calculate sample size and why. Clin Orthop Surg. 2013;5(3):235-42.

57. Mason RJ, Broaddus VC, Martin TR, King TE, Schraufnagel DE, Murray JF, et al. Murray and Nadel's textbook of respiratory medicine. 5th ed. Philadelphia: Saunders; 2010

58. Baedorf Kassis E, Loring SH, Talmor D. Esophageal pressure: research or clinical tool? Medizinische Klinik - Intensivmedizin und Notfallmedizin. 2018;113(1):13-20.

59. Talmor D, Sarge T, O'Donnell CR, Ritz R, Malhotra A, Lisbon A, et al. Esophageal and transpulmonary pressures in acute respiratory failure. Crit Care Med. 2006;34:1389-94.

60. Brochard L, Slutsky A, Pesenti A. Mechanical ventilation to minimize progression of lung injury in acute respiratory failure. Am J Respir Crit Care Med. 2016;195(4):438-42.

61. Brenner DJ, Hall EJ. Computed tomography — an increasing source of radiation exposure. N Engl J Med. 2007;357(22):2277-84

62. Chase JG, Moeller K, Shaw G, Schranz C, Chiew YS, Desaive T. When the value of gold is zero. BMC Res Notes. 2014;7(1):404.

63. Desai SR, Hansell DM. Lung imaging in the adult respiratory distress syndrome: current practice and new insights. Intensive Care Med. 1997;23(1):7-15.

64. Trotman-Dickenson B. Radiology in the intensive care unit (Part 2). J Intensive Care Med. 2003;18(5):239-52.

65. Trotman-Dickenson B. Radiology in the intensive care unit (Part I). J Intensive Care Med. 2003;18(4):198-210.

66. Slutsky AS, Hudson LD. PEEP or no PEEP_lung recruitment may be the solution. N Engl J Med. 2006;354(17):1839-41.

67. Adler A, Shinozuka N, Berthiaume Y, Guardo R, Bates JHT. Electrical impedance tomography can monitor dynamic hyperinflation in dogs. J Appl Physiol. 1998;84(2):726-32.

68. Zhao Z, Steinmann D, Frerichs I, Guttmann J, Moller K. PEEP titration guided by ventilation homogeneity: a feasibility study using electrical impedance tomography. Crit Care. 2010;14:R8.

69. Kobylianskii J, Murray A, Brace D, Goligher E, Fan E. Electrical impedance tomography in adult patients undergoing mechanical ventilation: a systematic review. J Crit Care. 2016:35:33-50.

70. Lobo B, Hermosa C, Abella A, Gordo F. Electrical impedance tomography. Ann TransI Med. 2018;6(2):26.

71. Meier T, Luepschen H, Karsten J, Leibecke T, Grossherr M, Gehring H, et al. Assessment of regional lung recruitment and derecruitment during a PEEP trial based on electrical impedance tomography. Intensive Care Med. 2008:34:543-50.

72. Dargaville PA, Rimensberger PC, Frerichs I. Regional tidal ventilation and compliance during a stepwise vital capacity manoeuvre. Intensive Care Med. 2010;36(11):1953-61.

73. Franchineau G, Bréchot N, Lebreton G, Hekimian G, Nieszkowska A, Trouillet J-L, et al. Bedside contribution of electrical impedance tomography to set positive end-expiratory pressure for ECMO-treated severe ARDS patients. Am J Respir Crit Care Med. 2017;196:447-57.

74. Costa ELV, Borges JB, Melo A, Suarez-Sipmann F, Toufen C, Bohm SH, et al. Bedside estimation of recruitable alveolar collapse and hyperdistension by electrical impedance tomography. Intensive Care Med. 2009:35(6):1132-7.

75. Fagerberg A, Söndergaard S, Karason S, Aneman A. Electrical impedence tomography and heterogeneity of pulmonary perfusion and ventilation in porcine acute lung injury. Acta Anaesthesiol Scand. 2009;53(10):1300-9.

76. Frerichs I, Amato MBP, van Kaam AH, Tingay DG, Zhao Z, Grychtol B, et al. Chest electrical impedance tomography examination, data analysis, terminology, clinical use and recommendations: consensus statement of the translational eit development study group. Thorax. 2017;72(1):83-93.

77. Knaus WA, Draper EA, Wagner DP, Zimmerman JE. APACHE II: a severity of disease classification system. Crit Care Med. 1985;13:818-29.

78. Knaus WA, Wagner DP, Draper EA, Zimmerman JE, Bergner M, Bastos PG, et al. The apache iii prognostic system risk prediction of hospital mortality for critically ill hospitalized adults. Chest J. 1991;100(6):1619-36.

79. Zimmerman JE, Kramer AA, McNair DS, Malila FM. Acute physiology and chronic health evaluation (APACHE) IV: hospital mortality assessment for today's critically ill patients. Crit Care Med. 2006:34(5):1297-310.

80. Le Gall J-R, Loirat P, Alperovitch A, Glaser P, Granthil C, Mathieu D, et al. A simplified acute physiology score for ICU patients. Crit Care Med. 1984;12(11):975-7.

81. Le Gall J, Lemeshow S, Saulnier F. A new simplified acute physiology score (saps ii) based on a european/north american multicenter study. JAMA. 1993;270(24):2957-63. 
82. Vincent J-L, Moreno R, Takala J, Willatts S, De Mendonça A, Bruining H, et al. The SOFA (Sepsis-related Organ Failure Assessment) score to describe organ dysfunction/failure. Intensive Care Med. 1996;22(7):707-10.

83. Zilberberg MD, Epstein SK. Acute lung injury in the medical ICU. Comorbid conditions, age, etiology, and hospital outcome. Am J Respir Crit Care Med. 1998;157(4):1159-64.

84. Adams AB, Simonson DA, Dries DJ. Ventilatory-induced lung injury. Respir Care Clin N Am. 2003;9(3):343-62.

85. Ricard JD, Dreyfuss D, Saumon G. Ventilator-induced lung injury. Eur Respir J. 2003;22(42_suppl):2s-9s.

86. Gajic O, Dara SI, Mendez JL, Adesanya AO, Festic E, Caples SM, et al. Ventilator-associated lung injury in patients without acute lung injury at the onset of mechanical ventilation. Crit Care Med. 2004;32(9):1817-24.

87. Moloney ED, Griffiths MJD. Protective ventilation of patients with acute respiratory distress syndrome. $\mathrm{Br} J$ Anaesth. 2004;92(2):261-70.

88. Carney D, DiRocco J, Nieman G. Dynamic alveolar mechanics and ventilator-induced lung injury. Crit Care Med. 2005;33(3):S122-8.

89. Parsons PE, Eisner MD, Thompson BT, Matthay MA, Ancukiewicz M, Bernard GR, et al. Lower tidal volume ventilation and plasma cytokine markers of inflammation in patients with acute lung injury. Crit Care Med. 2005;33(1):1-6.

90. Villar J. Ventilator or physician-induced lung injury? Minerva Anestesiol. 2005;71(6):255-8.

91. Pavone L, Albert S, DiRocco J, Gatto L, Nieman G. Alveolar instability caused by mechanical ventilation initially damages the nondependent normal lung. Crit Care. 2007;11(5):R104.

92. Cox CE, Carson SS, Govert JA, Chelluri L, Sanders GD. An economic evaluation of prolonged mechanical ventilation. Crit Care Med. 2007;35(8):1918-27.

93. Dreyfuss D, Saumon G. Barotrauma is volutrauma, but which volume is the one responsible? [editorial]. Intensive Care Med. 1992:18:139.

94. Andrews PL, Sadowitz B, Kollisch-Singule M, Satalin J, Roy S, Snyder K, et al. Alveolar instability (atelectrauma) is not identified by arterial oxygenation predisposing the development of an occult ventilator-induced lung injury. Intensive Care Med Exp. 2015;3(1):16.

95. Fan E, Villar J, Slutsky AS. Novel approaches to minimize ventilator-induced lung injury. BMC Med. 2013;11(1):85.

96. Weg JG, Anzueto A, Balk RA, Wiedemann HP, Pattishall EN, Schork MA, et al. The relation of pneumothorax and other air leaks to mortality in the acute respiratory distress syndrome. N Engl J Med. 1998;338(6):341-6.

97. Stewart TE, Meade MO, Cook DJ, Granton JT, Hodder RV, Lapinsky SE, et al. Evaluation of a ventilation strategy to prevent barotrauma in patients at high risk for acute respiratory distress syndrome. N Engl J Med. 1998;338(6):355-61.

98. Mols G, Priebe HJ, Guttmann J. Alveolar recruitment in acute lung injury. BJA Br J Anaesth. 2006;96(2):156-66.

99. Marini JJ, Gattinoni L. Ventilatory management of acute respiratory distress syndrome: a consensus of two. Crit Care Med. 2004;32:250-5.

100. Gattinoni L, Carlesso E, Cadringher P, Valenza F, Vagginelli F, Chiumello D. Physical and biological triggers of ventilator-induced lung injury and its prevention. Eur Respir J. 2003;22(47 - suppl):15s-25s.

101. Ferguson ND, Cook DJ, Guyatt GH, Mehta S, Hand L, Austin P, et al. High-frequency oscillation in early acute respiratory distress syndrome. N Engl J Med. 2013;368(9):795-805.

102. Slutsky AS, Tremblay LN. Multiple system organ failure. Is mechanical ventilation a contributing factor? Am J Respir Crit Care Med. 1998;157:1721-5.

103. Murphy DB, Cregg N, Tremblay L, Engelberts D, Laffey JG, Slutsky AS, et al. Adverse ventilatory strategy causes pulmonary-to-systemic translocation of endotoxin. Am J Respir Crit Care Med. 2000;162(1):27-33.

104. Cook DJ, Walter SD, Cook RJ, Griffith LE, Guyatt GH, Leasa D, et al. Incidence of and risk factors for ventilator-associated pneumonia in critically ill patients. Ann Intern Med. 1998;129:433-40.

105. Chiew YS, Chase JG, Shaw G, Sundaresan A, Desaive T. Model-based PEEP optimisation in mechanical ventilation. BioMed Eng OnLine. 2011;10(1):111.

106. Ware LB, Matthay MA. The acute respiratory distress syndrome. N Engl J Med. 2000;342(18):1334-49.

107. Matthay M, Ware L, Zimmerman G. The acute respiratory distress syndrome. J Clin Investig. 2012;122:2731-40.

108. Artigas A, Bernard Gordon R, Carlet J, Dreyfuss D, Gattinoni L, Hudson L, et al. The American-European Consensus Conference on ARDS, part 2. Ventilatory, pharmacologic, supportive therapy, study design strategies, and issues related to recovery and remodeling. Am J Respir Crit Care Med. 1998;157(4):1332-47.

109. The ARDS Definition Task Force. Acute respiratory distress syndrome: the Berlin definition. JAMA J Am Med Assoc. 2012;307(23):2526-33.

110. Obara H, Tanaka O, Hoshino Y, Kaetsu H, Maekawa N, Iwai S. One-lung ventilation. Anaesthesia. 1986:41(10):1007-10.

111. Sigurdsson MI, Sigvaldason K, Gunnarsson TS, Moller A, Sigurdsson GH. Acute respiratory distress syndrome: nationwide changes in incidence, treatment and mortality over 23 years. Acta Anaesthesiol Scand. 2013;57(1):37-45.

112. Rubenfeld GD, Herridge MS. Epidemiology and outcomes of acute lung injury. Chest. 2007;131:554-62.

113. Fan E, Wilcox ME, Brower RG, Stewart TE, Mehta S, Lapinsky SE, et al. Recruitment maneuvers for acute lung injury. Am J Respir Crit Care Med. 2008;178(11):1156-63.

114. Schoenfeld DA, Bernard GR, Network ftA. Statistical evaluation of ventilator-free days as an efficacy measure in clinical trials of treatments for acute respiratory distress syndrome. Crit Care Med. 2002;30(8):1772-7.

115. Bernard GR, Artigas A, Brigham KL, Carlet J, Falke K, Hudson L, et al. The American-European Consensus Conference on ARDS. Definitions, mechanisms, relevant outcomes, and clinical trial coordination. Am J Respir Crit Care Med. 1994;149:818-24.

116. Burleson BS, Maki ED. Acute respiratory distress syndrome. J Pharm Pract. 2005;18(2):118-31.

117. Costa ELV, Amato MBP. The new definition for acute lung injury and acute respiratory distress syndrome: is there room for improvement? Curr Opin Crit Care. 2013;19(1):16-23.

118. Barbas CSV, Isola AM, Caser EB. What is the future of acute respiratory distress syndrome after the Berlin definition? Curr Opin Crit Care. 2014;20(1):10-6. 
119. Terragni P, Faggiano C, Ranieri VM. Extracorporeal membrane oxygenation in adult patients with acute respiratory distress syndrome. Curr Opin Crit Care. 2014;20(1):86-91.

120. Phillips C. The Berlin definition: real change or the emperor's new clothes? Crit Care. 2013;17(4):174.

121. Estenssoro E, Dubin A, Laffaire E, Canales H, Sáenz G, Moseinco M, et al. Impact of positive end-expiratory pressure on the definition of acute respiratory distress syndrome. Intensive Care Med. 2003;29(11):1936-42.

122. Villar J, Pérez-Méndez L, López J, Belda J, Blanco J, Saralegui I, et al. An early PEEP/FiO2 trial identifies different degrees of lung injury in patients with acute respiratory distress syndrome. Am J Respir Crit Care Med. 2007;176(8):795-804.

123. Villar J, Kacmarek RM. The American-European Consensus Conference definition of the acute respiratory distress syndrome is dead, long live positive end-expiratory pressure! Medicina Intensiva. 2012;36(8):571-5.

124. Rittayamai N, Brochard L. Recent advances in mechanical ventilation in patients with acute respiratory distress syndrome. Eur Respir Rev. 2015;24(135):132-40.

125. Grasso S, Mascia L, Del Turco M, Malacarne P, Giunta F, Brochard L, et al. Effects of recruiting maneuvers in patients with acute respiratory distress syndrome ventilated with protective ventilatory strategy. Anesthesiology. 2002:96:795-802.

126. Rocco PRM, Pelosi P, De Abreu MG. Pros and cons of recruitment maneuvers in acute lung injury and acute respiratory distress syndrome. Expert Rev Respir Med. 2010;4(4):479-89.

127. Carvalho A, Jandre F, Pino A, Bozza F, Salluh J, Rodrigues R, et al. Positive end-expiratory pressure at minimal respiratory elastance represents the best compromise between mechanical stress and lung aeration in oleic acid induced lung injury. Crit Care. 2007;11(4):R86.

128. Odenstedt H, Lindgren S, Olegard C, Erlandsson K, Lethvall S, Aneman A, et al. Slow moderate pressure recruitment maneuver minimizes negative circulatory and lung mechanic side effects: evaluation of recruitment maneuvers using electric impedance tomography. Intensive Care Med. 2005;31:1706-14.

129. Suarez-Sipmann F, Bohm SH, Tusman G, Pesch T, Thamm O, Reissmann H, et al. Use of dynamic compliance for open lung positive end-expiratory pressure titration in an experimental study. Crit Care Med. 2007;35:214-21.

130. The ARDS Network. Effects of recruitment maneuvers in patients with acute lung injury and acute respiratory distress syndrome ventilated with high positive end-expiratory pressure. Crit Care Med. 2003;31(11):2592-7.

131. Hodgson C, Goligher EC, Young ME, Keating JL, Holland AE, Romero L, et al. Recruitment manoeuvres for adults with acute respiratory distress syndrome receiving mechanical ventilation. Cochrane Database Syst Rev. 2016;11:CD006667.

132. Goligher EC, Hodgson CL, Adhikari NKJ, Meade MO, Wunsch H, Uleryk E, et al. Lung recruitment maneuvers for adult patients with acute respiratory distress syndrome. a systematic review and meta-analysis. Ann Am Thorac Soc. 2017;14(4):S304-11.

133. Suter P, Fairley B, Isenberg M. Optimum end-expiratory airway pressure in patients with acute pulmonary failure. $N$ Engl J Med. 1975;292(6):284-9.

134. Suter PM, Fairley HB, Isenberg MD. Effect of tidal volume and positive end-expiratory pressure on compliance during mechanical ventilation. Chest. 1978;73:158-62.

135. Venegas JG, Harris RS, Simon BA. A comprehensive equation for the pulmonary pressure-volume curve. J Appl Physiol. 1998;84:389-95.

136. Harris RS, Hess DR, Venegas JG. An objective analysis of the pressure-volume curve in the acute respiratory distress syndrome. Am J Respir Crit Care Med. 2000;161:432-9.

137. Lu Q, Rouby J-J. Measurement of pressure-volume curves in patients on mechanical ventilation: methods and significance. Crit Care. 2000;4(2):91-100.

138. Harris RS. Pressure-volume curves of the respiratory system. Respir Care. 2005:50(1):78-98.

139. Stahl CA, Moller K, Schumann S, Kuhlen R, Sydow M, Putensen C, et al. Dynamic versus static respiratory mechanics in acute lung injury and acute respiratory distress syndrome. Crit Care Med. 2006;34:2090-8.

140. Lichtwarck-Aschoff M, Kessler V, Sjostrand UH, Hedlund A, Mols G, Rubertsson S, et al. Static versus dynamic respiratory mechanics for setting the ventilator. Br J Anaesth. 2000;85(4):577-86.

141. Karason S, Sondergaard S, Lundin S, Wiklund J, Stenqvist O. Evaluation of pressure/volume loops based on intratracheal pressure measurements during dynamic conditions. Acta Anaesthesiol Scand. 2000;44(5):571-7.

142. Chatburn RL. Fundamentals of mechanical ventilation. A short course in the theory and application of mechanical ventilators. Cleveland Heights: Mandu Press Ltd; 2003.

143. Lambermont B, Ghuysen A, Janssen N, Morimont P, Hartstein G, Gerard P, et al. Comparison of functional residual capacity and static compliance of the respiratory system during a positive end-expiratory pressure (PEEP) ramp procedure in an experimental model of acute respiratory distress syndrome. Crit Care. 2008;12(4):R91.

144. Santos A, Lucchetta L, Monge-Garcia MI, Borges JB, Tusman G, Hedenstierna G, et al. The open lung approach improves pulmonary vascular mechanics in an experimental model of acute respiratory distress syndrome. Crit Care Med. 2017:45(3):e298-305.

145. Kacmarek RM, Villar J, Sulemanji D, Montiel R, Ferrando C, Blanco J, et al. Open lung approach for the acute respiratory distress syndrome: a pilot, randomized controlled trial*. Crit Care Med. 2016;44(1):32-42.

146. Ferrando C, Suarez-Sipmann F, Tusman G, León I, Romero E, Gracia E, et al. Open lung approach versus standard protective strategies: effects on driving pressure and ventilatory efficiency during anesthesia—a pilot, randomized controlled trial. PLOS ONE. 2017;12(5):e0177399.

147. Spieth PM, Güldner A, Carvalho AR, Kasper M, Pelosi P, Uhlig S, et al. Open lung approach vs acute respiratory distress syndrome network ventilation in experimental acute lung injury. Br J Anaesth. 2011;107(3):388-97.

148. Suki B, Alencar AM, Sujeer MK, Lutchen KR, Collins JJ, Andrade JS, et al. Life-support system benefits from noise. Nature. 1998;393(6681):127-8.

149. Funk D, Graham MR, Girling L, Thliveris J, McManus B, Walker E, et al. A comparison of biologically variable ventilation to recruitment manoeuvres in a porcine model of acute lung injury. Respir Res. 2004;5(1):22.

150. Mutch WA, Eschun GM, Kowalski SE, Graham MR, Girling LG, Lefevre GR. Biologically variable ventilation prevents deterioration of gas exchange during prolonged anaesthesia. BJA Br J Anaesth. 2000;84(2):197-203. 
151. Gama de Abreu M, Spieth PM, Pelosi P, Carvalho AR, Walter C, Schreiber-Ferstl A, et al. Noisy pressure support ventilation: a pilot study on a new assisted ventilation mode in experimental lung injury. Crit Care Med. 2008;36(3):818-27.

152. Spieth PM, Carvalho AR, Pelosi P, Hoehn C, Meissner C, Kasper M, et al. Variable tidal volumes improve lung protective ventilation strategies in experimental lung injury. Am J Respir Crit Care Med. 2009;179(8):684-93.

153. Spieth PM, Carvalho AR, Güldner A, Kasper M, Schubert R, Carvalho NC, et al. Pressure support improves oxygenation and lung protection compared to pressure-controlled ventilation and is further improved by random variation of pressure support. Crit Care Med. 2011;39(4):746-55.

154. Spieth PM, Carvalho AR, Güldner A, Pelosi P, Kirichuk O, Koch T, et al. Effects of different levels of pressure support variability in experimental lung injury. Anesthesiology. 2009;110(2):342-50.

155. Sinderby C, Navalesi P, Beck J, Skrobik Y, Comtois N, Friberg S, et al. Neural control of mechanical ventilation in respiratory failure. Nat Med. 1999;5(12):1433-6.

156. Piquilloud L, Vignaux L, Bialais E, Roeseler J, Sottiaux T, Laterre P-F, et al. Neurally adjusted ventilatory assist improves patient-ventilator interaction. Intensive Care Med. 2011;37(2):263-71.

157. Moorhead K, Piquilloud L, Lambermont B, Roeseler J, Chiew Y, Chase JG, et al. NAVA enhances tidal volume and diaphragmatic electro-myographic activity matching: a Range 90 analysis of supply and demand. J Clin Monit Comput. 2013;27(1):61-70.

158. Moss KSM. Neurally adjusted ventilatory assist: insufficient evidence of broad clinical outcomes. Respir Care 2013;58(5):884-5.

159. Schmidt M, Kindler F, Cecchini J, Poitou T, Morawiec E, Persichini R, et al. Neurally adjusted ventilatory assist and proportional assist ventilation both improve patient-ventilator interaction. Crit Care. 2015;19(1):56.

160. Schmidt M, Demoule A, Cracco C, Gharbi A, Fiamma M-N, Straus C, et al. Neurally adjusted ventilatory assist increases respiratory variability and complexity in acute respiratory failure. Anesthesiology. 2010;112(3):670-81. https://doi.org/10.1097/ALN.0b013e3181cea375.

161. Chiew Y, Chase J, Lambermont B, Roeseler J, Pretty C, Bialais E, et al. Effects of Neurally Adjusted Ventilatory Assist (NAVA) levels in non-invasive ventilated patients: titrating NAVA levels with electric diaphragmatic activity and tidal volume matching. BioMed Eng OnLine. 2013;12(1):61.

162. Rozé H, Lafrikh A, Perrier V, Germain A, Dewitte A, Gomez F, et al. Daily titration of neurally adjusted ventilatory assist using the diaphragm electrical activity. Intensive Care Med. 2011;37(7):1087-94.

163. Terzi N, Piquilloud L, Roze H, Mercat A, Lofaso F, Delisle S, et al. Clinical review: update on neurally adjusted ventilatory assist—report of a round-table conference. Crit Care. 2012;16(3):225

164. Derdak S, Mehta S, Stewart TE, Smith T, Rogers M, Buchman TG, et al. High-frequency oscillatory ventilation for acute respiratory distress syndrome in adults: a randomized, controlled trial. Am J Respir Crit Care Med. 2002;166:801-8

165. Gu X-L, Wu G-N, Yao Y-W, Shi D-H, Song Y. In adult acute respiratory distress syndrome patients, is high-frequency oscillatory ventilation more effective and safer than conventional protective ventilation? A meta-analysis of randomized controlled trials. Crit Care. 2014;18(3):R111.

166. Young D, Lamb SE, Shah S, MacKenzie I, Tunnicliffe W, Lall R, et al. High-frequency oscillation for acute respiratory distress syndrome. N Engl J Med. 2013;368(9):806-13.

167. Räsänen J, Cane RD, Downs JB, Hurst JM, Jousela IT, Kirby RR, et al. Airway pressure release ventilation during acute lung injury: a prospective multicenter trial. Crit Care Med. 1991;19(10):1234-41.

168. Sydow M, Burchardi H, Ephraim E, Zielmann S, Crozier TA. Long-term effects of two different ventilatory modes on oxygenation in acute lung injury. Comparison of airway pressure release ventilation and volume-controlled inverse ratio ventilation. Am J Respir Crit Care Med. 1994;149:1550-6.

169. Putensen C, Mutz Norbert J, Putensen-Himmer G, Zinserling J. Spontaneous breathing during ventilatory support improves ventilation-perfusion distributions in patients with acute respiratory distress syndrome. Am J Respir Crit Care Med. 1999;159(4):1241-8.

170. Jain SV, Kollisch-Singule M, Sadowitz B, Dombert L, Satalin J, Andrews P, et al. The 30-year evolution of airway pressure release ventilation (APRV). Intensive Care Med Exp. 2016;4(1):11.

171. Fuller B, Mohr N, Drewry A, Carpenter C. Lower tidal volume at initiation of mechanical ventilation may reduce progression to acute respiratory distress syndrome—a systematic review. Crit Care. 2013;17(1):R11.

172. van Drunen E, Chiew YS, Chase J, Shaw G, Lambermont B, Janssen N, et al. Expiratory model-based method to monitor ARDS disease state. BioMed Eng OnLine. 2013;12(1):57.

173. Arnal J-M, Wysocki M, Novotni D, Demory D, Lopez R, Donati S, et al. Safety and efficacy of a fully closed-loop control ventilation (IntelliVent-ASV ${ }^{\circledR}$ ) in sedated ICU patients with acute respiratory failure: a prospective randomized crossover study. Intensive Care Med. 2012;38(5):781-7.

174. Wolf GK, Gómez-Laberge C, Rettig JS, Vargas SO, Smallwood CD, Prabhu SP, et al. Mechanical ventilation guided by electrical impedance tomography in experimental acute lung injury*. Crit Care Med. 2013;41(5):1296-304. https:// doi.org/10.1097/CCM.0b013e3182771516.

175. Bass C, Sajed D, Adedipe A, West TE. Pulmonary ultrasound and pulse oximetry versus chest radiography and arterial blood gas analysis for the diagnosis of acute respiratory distress syndrome: a pilot study. Crit Care. 2015;19(1):1-11.

176. Fab Corradi, Cc Brusasco, Pc Pelosi. Chest ultrasound in acute respiratory distress syndrome. Curr Opin Crit Care. 2014;20(1):98-103.

177. Dexheimer Neto FL, Dalcin PDTR, Teixeira C, Beltrami FG. Lung ultrasound in critically ill patients: a new diagnostic tool. Jornal Brasileiro de Pneumologia. 2012;38:246-56.

178. Vecchi V, Langer T, Bellomi M, Rampinelli C, Chung K, Cancio L, et al. Low-dose CT for quantitative analysis in acute respiratory distress syndrome. Crit Care. 2013;17(4):R183.

179. Sinderby C. Neurally adjusted ventilatory assist: insufficient evidence of broad clinical outcomes. Respir Care. 2013:58(11):e153-4 
180. Ambrosino N, Rossi A. Proportional assist ventilation (PAV): a significant advance or a futile struggle between logic and practice? Thorax. 2002;57(3):272-6.

181. Cordioli RL, Akoumianaki E, Brochard L. Nonconventional ventilation techniques. Curr Opin Crit Care. 2013;19(1):31-7.

182. Sinderby C, Liu S, Colombo D, Camarotta G, Slutsky A, Navalesi P, et al. An automated and standardized neural index to quantify patient-ventilator interaction. Crit Care. 2013;17(5):R239.

183. Pomprapa A, Schwaiberger D, Pickerodt P, Tjarks O, Lachmann B, Leonhardt S. Automatic protective ventilation using the ARDSNet protocol with the additional monitoring of electrical impedance tomography. Crit Care. 2014;18(3):R128.

184. Chase JG, Preiser J-C, Dickson JL, Pironet A, Chiew YS, Pretty CG, et al. Next-generation, personalised, model-based critical care medicine: a state-of-the art review of in silico virtual patient models, methods, and cohorts, and how to validation them. BioMed Eng OnLine. 2018;17(1):24.

185. Kretschmer J, Haunsberger T, Drost E, Koch E, Möller K. Simulating physiological interactions in a hybrid system of mathematical models. J Clin Monit Comput. 2014;28(6):513-23.

186. Tawhai MH, Bates JHT. Multi-scale lung modeling. J Appl Physiol. 2011;110(5):1466-72.

187. Bates J, Allen $\mathrm{G}$. The estimation of lung mechanics parameters in the presence of pathology: a theoretical analysis. Ann Biomed Eng. 2006;34(3):384-92.

188. Steimle KL, Mogensen ML, Karbing DS, Bernardino de la Serna J, Andreassen S. A model of ventilation of the healthy human lung. Comput Methods Programs Biomed. 2011;101(2):144-55.

189. Lucangelo U, Bernabè F, Blanch L. Lung mechanics at the bedside: make it simple. Curr Opin Crit Care. 2007;13(1):64-72.

190. Schranz C, Docherty PD, Chiew YS, Chase JG, Moller K. Structural identifiability and practical applicability of an alveolar recruitment model for ARDS patients. Biomed Eng IEEE Trans. 2012;59(12):3396-404.

191. Rees SE. The intelligent ventilator (INVENT) project: the role of mathematical models in translating physiological knowledge into clinical practice. Comput Methods Programs Biomed. 2011;104(Supplement 1(0)):S1-29.

192. Damanhuri NS, Chiew YS, Othman NA, Docherty PD, Pretty CG, Shaw GM, et al. Assessing respiratory mechanics using pressure reconstruction method in mechanically ventilated spontaneous breathing patient. Comput Methods Programs Biomed. 2016;130:175-85.

193. Pomprapa A, Schwaiberger D, Lachmann B, Leonhardt S. A mathematical model for carbon dioxide elimination: an insight for tuning mechanical ventilation. Eur J Appl Physiol. 2014;114(1):165-75.

194. Sundaresan A, Yuta T, Hann CE, Geoffrey Chase J, Shaw GM. A minimal model of lung mechanics and modelbased markers for optimizing ventilator treatment in ARDS patients. Comput Methods Programs Biomed. 2009:95(2):166-80.

195. Sundaresan A, Geoffrey Chase J, Hann CE, Shaw GM. Dynamic functional residual capacity can be estimated using a stress-strain approach. Comput Methods Programs Biomed. 2011;101(2):135-43.

196. Brochard L, Martin G, Blanch L, Pelosi P, Belda FJ, Jubran A, et al. Clinical review: respiratory monitoring in the ICU—a consensus of 16. Crit Care. 2012:16(2):219.

197. Sundaresan A, Chase J, Shaw G, Chiew YS, Desaive T. Model-based optimal PEEP in mechanically ventilated ARDS patients in the Intensive Care Unit. BioMed Eng OnLine. 2011;10(1):64

198. Bates JHT. Lung mechanics: an inverse modeling approach. New York: Cambridge University Press; 2009. p. 2009.

199. Ben-Tal A. Computational models for the study of heart-lung interactions in mammals. Wiley Interdiscip Rev Syst Biol Med. 2012;4(2):163-70.

200. Schwaiberger D, Pickerodt PA, Pomprapa A, Tjarks O, Kork F, Boemke W, et al. Closed-loop mechanical ventilation for lung injury: a novel physiological-feedback mode following the principles of the open lung concept. J Clin Monit Comput. 2017;32:493-502.

201. Zhao Z, Steinmann D, Frerichs I, Guttmann J, Möller K. PEEP titration guided by ventilation homogeneity: a feasibility study using electrical impedance tomography. Crit Care. 2010;14(1):R8.

202. Schranz C, Becher T, Schädler D, Weiler N, Möller K. Model-based setting of inspiratory pressure and respiratory rate in pressure-controlled ventilation. Physiol Meas. 2014;35(3):383.

203. Karbing DS, Allerød C, Thorgaard P, Carius A-M, Frilev L, Andreassen S, et al. Prospective evaluation of a decision support system for setting inspired oxygen in intensive care patients. J Crit Care. 2010;25(3):367-74.

204. Karbing DS, Spadaro S, Rees SE, Volta CA. Prospective evaluation of a decision support system providing advice on ventilator settings of: inspiratory oxygen, delivered pressure or volume, frequency and peep. Intensive Care Med Exp. 2015;3(Suppl 1):A672.

205. Rees SE, Karbing DS. Model-based optimization of peep, a strategy and its implementation. Intensive Care Med Exp. 2015;3(Suppl 1):A681.

206. Rees SE, Karbing DS, editors. Model-based advice for mechanical ventilation: from research (INVENT) to product (Beacon Caresystem). In: 2015 37th annual international Conference of the IEEE engineering in medicine and biology society (EMBC); 2015 25-29 Aug; 2015.

207. Szlavecz A, Chiew Y, Redmond D, Beatson A, Glassenbury D, Corbett S, et al. The clinical utilisation of respiratory elastance software (CURE Soft): a bedside software for real-time respiratory mechanics monitoring and mechanical ventilation management. BioMed Eng OnLine. 2014;13(1):140.

208. Chiew YS, Tan CP, Chase JG, Chiew YW, Desaive T, Ralib AM, et al. Assessing mechanical ventilation asynchrony through iterative airway pressure reconstruction. Comput Methods Programs Biomed. 2018;157:217-24

209. Junhasavasdikul D, Telias I, Grieco DL, Chen L, Gutierrez CM, Piraino T, et al. Expiratory flow limitation during mechanical ventilation. Chest. 2018;154:948-62.

210. Oostveen E, MacLeod D, Lorino H, Farré R, Hantos Z, Desager K, et al. The forced oscillation technique in clinical practice: methodology, recommendations and future developments. Eur Respir J. 2003;22(6):1026-41.

211. Lu QIN, Vieira SRR, Richecoeur J, Puybasset L, Kalfon P, Coriat P, et al. A simple automated method for measuring pressure-volume curves during mechanical ventilation. Am J Respir Crit Care Med. 1999;159(1):275-82. 
212. Docherty PD, Schranz C, Chiew Y-S, Möller K, Chase JG. Reformulation of the pressure-dependent recruitment model (PRM) of respiratory mechanics. Biomed Signal Process Control. 2014;12:47-53.

213. Pintado M-C, de Pablo R, Trascasa M, Milicua J-M, Rogero S, Daguerre M, et al. Individualized PEEP setting in subjects with ARDS: a randomized controlled pilot study. Respir Care. 2013;58(9):1416-23.

214. Chiew YS, Pretty C, Docherty PD, Lambermont B, Shaw GM, Desaive T, et al. Time-varying respiratory system elastance: a physiological model for patients who are spontaneously breathing. PLoS ONE. 2015;10(1):e0114847.

215. Chiew YS, Chase JG, Lambermont B, Janssen N, Schranz C, Moeller K, et al. Physiological relevance and performance of a minimal lung model — an experimental study in healthy and acute respiratory distress syndrome model piglets. BMC Pulm Med. 2012;12(1):59.

216. Riedlinger A, Kretschmer J, Moller K. On the practical identifiability of a two-parameter model of pulmonary gas exchange. BioMed Eng OnLine. 2015;14(1):82.

217. Karbing D, Kjaergaard S, Smith B, Espersen K, Allerod C, Andreassen S, et al. Variation in the PaO2/FiO2 ratio with FiO2: mathematical and experimental description, and clinical relevance. Crit Care. 2007;11(6):R118.

- fast, convenient online submission

- thorough peer review by experienced researchers in your field

- rapid publication on acceptance

- support for research data, including large and complex data types

- gold Open Access which fosters wider collaboration and increased citations

- maximum visibility for your research: over 100M website views per year

At BMC, research is always in progress.

Learn more biomedcentral.com/submissions 